\title{
1 An antibody targeting the N-terminal domain of SARS-CoV-2 disrupts the spike trimer
}

3 Naveenchandra Suryadevara ${ }^{1}$, Andrea R. Shiakolas ${ }^{1,2}$, Laura A. VanBlargan ${ }^{3}$, Elad Binshtein ${ }^{1}$,

4 Rita E. Chen ${ }^{3,4}$, James Brett Case ${ }^{3}$, Kevin J. Kramer ${ }^{1,2}$, Erica Armstrong ${ }^{1}$, Luke Myers ${ }^{1}$, Andrew

5 Trivette $^{1}$, Christopher Gainza ${ }^{1}$, Rachel S. Nargi ${ }^{1}$, Christopher N. Selverian ${ }^{5}$, Edgar Davidson $^{5}$,

6 Benjamin J. Doranz ${ }^{5}$, Summer M. Diaz ${ }^{1}$, Laura S. Handal ${ }^{1}$, Robert H. Carnahan ${ }^{1,6}$, Michael S.

7 Diamond ${ }^{3,4,7}$, Ivelin S. Georgiev ${ }^{1,2}$, James E. Crowe, Jr. ${ }^{1,2,6, *}$

$8{ }^{1}$ Vanderbilt Vaccine Center, Vanderbilt University Medical Center, Nashville, TN, 37232 ,

9 USA

$10{ }^{2}$ Department of Pathology, Microbiology and Immunology, Vanderbilt University Medical

11 Center, Nashville, TN, 37232, USA

$12{ }^{3}$ Department of Medicine, Washington University School of Medicine, Saint Louis, MO, $13 \quad 63110$ USA

$14{ }^{4}$ Department of Pathology \& Immunology, Washington University School of Medicine, Saint 15 Louis, MO, 63110 USA

$16 \quad{ }^{5}$ Integral Molecular, Philadelphia, PA, 19104, USA

$17{ }^{6}$ Department of Pediatrics, Vanderbilt University Medical Center, Nashville, TN, 37232, USA

$18{ }^{7}$ Department of Molecular Microbiology, Washington University School of Medicine, Saint 19 Louis, MO, 63110, USA 
$21 *$ To whom correspondence should be addressed

\section{SUMMARY}

24 The protective human antibody response to the severe acute respiratory syndrome coronavirus 2

25 (SARS-CoV-2) virus focuses on the spike (S) protein which decorates the virion surface and

26 mediates cell binding and entry. Most SARS-CoV-2 protective antibodies target the receptor-

27 binding domain or a single dominant epitope ('supersite') on the $\mathrm{N}$ terminal domain (NTD).

28 Here, using the single B cell technology LIBRA-seq, we isolated a large panel of NTD-reactive

29 and SARS-CoV-2 neutralizing antibodies from an individual who had recovered from COVID-

30 19. We found that neutralizing antibodies to the NTD supersite commonly are encoded by the

31 IGHVI-24 gene, forming a genetic cluster that represents a public B cell clonotype. However, we

32 also discovered a rare human antibody, COV2-3434, that recognizes a site of vulnerability on the

33 SARS-CoV-2 S protein in the trimer interface and possesses a distinct class of functional

34 activity. COV2-3434 disrupted the integrity of S protein trimers, inhibited cell-to-cell spread of

35 virus in culture, and conferred protection in human ACE2 transgenic mice against SARS-CoV-2

36 challenge. This study provides insight about antibody targeting of the $\mathrm{S}$ protein trimer interface

37 region, suggesting this region may be a site of virus vulnerability.

Keywords: Coronavirus; SARS-CoV-2; Antibodies, Neutralizing; N-terminal domain. 


\section{INTRODUCTION}

42 During the COVID-19 pandemic, more than 150 vaccine candidates have been developed, but

43 only a few have been licensed. Most licensed vaccines encode the full-length spike (S) protein

44 including two stabilizing proline mutations (S2P) of SARS-CoV-2 (Baden et al., 2021; Polack

45 et al., 2020; Turner et al., 2021c) and have proven effective in protecting against SARS-CoV-

462 disease. Although SARS-CoV-2 vaccines have been developed at unprecedented speed,

47 several questions remain about efficacy and the durability of protective immunity associated

48 with serum neutralizing antibodies generated against the $\mathrm{S}$ protein. Efficacy studies are

49 complicated by the emergence of SARS-CoV-2 variants of concern (VOC) that can escape

50 some neutralizing antibodies. Antibodies that neutralize SARS-COV-2 VOC have been

51 studied broadly by many groups, both in terms of their potency and structure (Barnes et al.,

52 2020; Baum et al., 2020; Cerutti et al., 2021b; Chen et al., 2021b; Chi et al., 2020; Dong et

53 al., 2021; Hansen et al., 2020; McCallum et al., 2021; Pinto et al., 2020; Rogers et al., 2020;

54 Shi et al., 2020; Suryadevara et al., 2021; Turner et al., 2021b; Zost et al., 2020a). Similarly, it

55 has been reported that unrelated individuals can produce genetically and functionally similar

56 clones of antibodies ("public clonotypes") following infection or vaccination ((Chen et al.,

57 2021a; Robbiani et al., 2020; Soto et al., 2019; Yuan et al., 2020)18-22).

59 The receptor binding domain (RBD) of the $\mathrm{S}$ protein interacts with angiotensin-converting

61 cooperate with receptors or co-receptors, such as dendritic cell-specific intercellular adhesion 
62 molecule-3-grabbing non-integrin (DC-SIGN or CD209), neuropilin-1 (NRP-1), and liver-

63 /lymph-node-specific intracellular adhesion molecules-3 grabbing non-integrin (L-SIGN or

64 CD209L) to mediate viral attachment and enable SARS-CoV-2 infection via the established

65 ACE2 receptor pathway (Amraei et al., 2021; Cantuti-Castelvetri et al., 2020; Daly et al.,

66 2020; Lempp et al., 2021). Furthermore, the NTD of SARS-CoV-2 spike reportedly binds

67 biliverdin by recruitment of tetrapyrrole rings, to evade neutralization of SARS-CoV-2 by

68 some antibodies (Rosa et al., 2021). SARS-CoV-2 S appears to exhibit conformational

69 flexibility of divergent loop regions in the NTD to accommodate diverse glycan-rich host

70 sialosides that may allow it to infect host cells with wide tissue tropism (Awasthi et al., 2020).

71 Taken together, our understanding of the functional qualities of the human antibody response

72 against NTD is incomplete. We and other groups previously have identified potently

73 neutralizing NTD-specific mAbs targeting one major antigenic site (Cerutti et al., 2021b; Chi

74 et al., 2020; McCallum et al., 2021; Suryadevara et al., 2021; Voss et al., 2021; Wu et al.,

75 2020). Here, using the single-B-cell barcoding LIBRA-seq antibody discovery technology, we

76 performed targeted discovery of NTD-reactive antibodies from an individual who had

77 recovered from a previous SARS-CoV-2 infection. Our results indicate that a dominant

78 human B cell response to that major NTD antigenic site comprises clones encoded by

79 common variable gene segments (i.e., constitute a "public clonotype"). The scale of antibody

80 discovery possible with LIBRA-seq also allowed us to identify a rare clone with unusual

81 specificity and function.

82

\section{RESULTS}




\section{SARS-CoV-2 infection induces a strong response against NTD and durable neutralization}

titers. Peripheral blood samples were obtained following written informed consent from four subjects (D1988, D1989, D1995 and D1951) infected in the United States who tested PCRpositive for SARS-CoV-2 infection and one healthy donor (D269) who served as a negative control (Table S1). We isolated plasma or serum specimens from the five individuals and performed serum/plasma antibody ELISA binding assays using soluble proline-stabilized S ectodomain ( $\left.\mathrm{S} 2 \mathrm{P}_{\text {ecto }}\right), \mathrm{RBD}$, or NTD protein from $\mathrm{SARS}-\mathrm{CoV}-2$ or $\mathrm{S} 2 \mathrm{P}_{\text {ecto }}$ protein from SARSCoV. All subjects (except the negative control) had circulating antibodies that recognized each of the proteins tested, with the greatest reactivity against the SARS-CoV-2 S2P $\mathrm{P}_{\text {ecto }}$ RBD and NTD proteins (Fig. 1A). The serum antibody reactivity of one individual (D1989) was highest against the SARS-CoV-2 NTD protein (Fig. 1A). Consequently, we focused our efforts on identifying B cells from the blood samples of this individual, using sequential collections on day 18, 28, 58

97 and day 90 after onset of symptoms. This individual also possessed high serum neutralizing performed a serum-antibody focus reduction neutralization test (FRNT) using an authentic SARS-CoV-2 strain (WA/1/2020). The authentic virus assay gave similar results to the VSVbased assay (Fig. 1C). 
et al., 2019) to identify NTD-reactive B cells. This high-throughput technology enables

109 determination of $\mathrm{B}$ cell receptor sequence and antigen reactivity at single-cell level. The LIBRA-

110 seq antigen screening library included SARS-CoV-2 S protein stabilized in a prefusion

111 conformation (S6P $\mathrm{ecto}$ ) and NTD from SARS-CoV-2 (2019-nCoV), along with antigens from

112 other coronavirus strains and negative control antigens. We identified 347 NTD-specific B cells

113 from individual D1989 (day112). We recovered $108 \mathrm{~B}$ cells which expressed unique $\mathrm{V}_{\mathrm{H}}-\mathrm{JH}-$

114 CDRH3- $\mathrm{V}_{\mathrm{L}}-\mathrm{J}_{\mathrm{L}}-\mathrm{CDRL} 3$ clonotypes and gave LIBRA-seq scores above a threshold of 1 for

115 rNTD (Fig. 2A), and we were able to express 102 of these sequences as human mAbs. To

116 confirm the antigen specificity predicted by the LIBRA-seq score, we tested all expressed mAbs

117 for binding in ELISA to recombinant monomeric RBD or NTD of SARS-CoV-2 or trimeric

$118 \mathrm{~S}_{\mathrm{S}}$ ecto of SARS-CoV-2 or trimeric S2P $\mathrm{ecto}_{\text {of }} \mathrm{SARS-CoV}$ proteins. We confirmed the predicted

119 antigen specificity for greater than $90 \%$ of the clones (Fig. 2B). Most antibodies recognized

120 NTD protein, except for COV2-3454 which recognized RBD (Fig. 2B).

121

122 Additionally, using the RTCA method, we performed high-throughput neutralization assays with

123 VSV-S and identified 9 mAbs that showed either full (100\%) or partial (50 to $80 \%)$ neutralizing

124 capacity (Fig. 2B). Next, we analyzed the sequences of the variable region genes for the 102

125 expressed antibodies to assess the genetic diversity of antigen-specific B cell clonotypes

126 discovered. The expressed antibodies had diverse sequence features, including varied V- and J-

127 gene usage, CDR3 lengths, and somatic hypermutation levels for both the heavy and light chains

128 (Fig. S1a). After clustering these clones based on the inferred immunoglobulin heavy variable

129 (IGHV) gene, we noted that the IGHVI-24 and IGHVI-69 variable gene segments were used 
130 frequently in this individual's response (Fig. S1b). Five of the nine neutralizing mAbs are encoded by the IGHV1-24 gene segment and are clonally unrelated (Fig. 2C).

\section{Potently neutralizinge antibodies against NTD belong to public clonotypes.}

134 Next, we determined the binding activity of the panel of NTD-reactive neutralizing antibodies.

135 Using serial dilution studies, we determined the half-maximum effective concentration $\left(\mathrm{EC}_{50}\right)$ for

binding to the $\mathrm{S}_{6} \mathrm{P}_{\text {ecto }}$ trimer protein, in comparison with a known NTD-reactive mAb (4A8) or a

137 negative control dengue-specific antibody (rDENV-2D22). NTD-reactive neutralizing antibodies

138 exhibited varied binding profiles with a diverse range of $\mathrm{EC}_{50}$ values (Fig. 3A). We also tested

139 the panel of antibodies for binding to cell-surface-displayed S protein on SARS-CoV-2-infected

140 cells according to the gating strategy shown in Fig S2. Unexpectedly, the NTD-targeting mAbs

141 stained infected cells with greater intensity (higher median fluorescence intensity [MFI]) than a

142 previously described high-affinity RBD-reactive potently neutralizing mAb (COV2-2196) (Zost

143 et al., 2020a) (Fig. 3B). We also determined the inhibitory potency for representative mAbs in

144 the quantitative VSV-S-based neutralization assay (Fig. 3C). These results confirmed that the

145 LIBRA-seq technology efficiently identifies mAbs with the correct antigen specificity and that

146 some of the NTD-reactive mAbs potently neutralize VSV-S infection based on RTCA

147 neutralization ((Suryadevara et al., 2021; Zost et al., 2020a). Next, we chose chose COV2-3434

148 for further study with FRNT as it showed a distinct phenotype both in binding and rVSV

149 neutralization. We performed FRNTs for mAb COV2-3434 using strains SARS-CoV-2 D614G

150 and chimeric strains expressing the B.1.351 (Beta) spike in the WA1/2020 background (Wash-B

151 1.351) (Chen et al., 2021b). COV2-3434 neutralized both strains of SARS-CoV-2 in a dose-

152 dependent manner, with half-maximal inhibitory $\left(\mathrm{IC}_{50}\right)$ values of 5.5 or $32 \mu \mathrm{g} / \mathrm{mL}$, respectively 
153 (Fig. 3D). A comprehensive analysis of antibody variable gene sequences for SARS-CoV-2

154 human mAbs revealed that the IGHVI-24 gene segment is frequently used by vaccinated or 155 convalescent individuals when targeting the NTD (Table S2, Fig. S3). Nevertheless, the clones 156 recovered here were unique with diverse gene usage for both heavy and light chains. There was 157 no bias for a particular HCDR3 length that confers NTD-specificity. Additionally, the IGHVI-69 158 and IGHV3-53 gene segments are over-represented in both RBD- and NTD-specific antibodies 159 isolated from convalescent subjects. Of note, the IGHVI-69 gene-encoded antibodies that reacted 160 with NTD did not neutralize VSV-S, and the other $\mathrm{V}_{\mathrm{H}}$ genes used (IGHVI-2, IGHV3-23 and 161 IGHV3-53) encoded clones with only moderate neutralizing capacity. Thus, the most potently 162 neutralizing NTD-reactive antibodies isolated here were encoded by IGHV1-24.

164 To determine if the function of IGHVI-24-encoded antibodies identified in this study was due to 165 germline-encoded reactivity or the result of somatic mutations, we engineered 'germline 166 reversion' (GR) recombinant antibodies that were reverted at residues that differed from the 167 germline gene segments either in the heavy chain (GR-HC) or in both heavy and light chains 168 (GR). After alignment of the sequences of IGHV1-24-encoded clones the with germline gene 169 segment IGHV1-24, we chose the mAb COV2-3443 for further study, as it was the antibody with 170 the fewest somatic mutations. We tested if the GR mAb shared similar functional properties with 171 its somatically-mutated counterparts for binding to S protein or VSV-S neutralization. The 172 COV2-3443 GR-HC mAb retained some binding and neutralization capacity, whereas COV21733443 GR completely lost binding and neutralization capacity, suggesting that the functional 174 activities required some or all of the somatic mutations present in the matured antibody (Fig. 3 $175 \mathbf{E}, \mathbf{F})$. 
COV2-3434 maps to a distinct site from the NTD supersite. We next defined antigenic sites

178

179

180

181

182

183

184

185

186

187

188

189

190

191

192

193

194

195

196

197

198

on the NTD by competition-binding analysis. We used SARS-CoV-2 $6 \mathrm{P}_{\text {ecto }}$ protein to screen for NTD-reactive neutralizing mAbs that competed for binding with each other or with the previously described NTD-reactive mAbs COV2-2676 and COV2-2489 that recognize known epitope on NTD (10). We also used the previously described RBD-reactive neutralizing (COV22196 and COV2-2130) or non-neutralizing (rCR3022) mAbs as controls. We identified two groups of competing mAbs in the NTD (Fig. 4A). The first group competed for binding to the known NTD supersite, which we and others have described previously (Cerutti et al., 2021b; Chi et al., 2020; McCallum et al., 2021; Suryadevara et al., 2021). The second competition group contains a single mAb (COV2-3434) that bound to a site distinct from the epitope of all other NTD-reactive mAbs (Fig. 4A). We also tested competition of COV2-3434 mAb with the recently reported antibody 5-7, which binds a hydrobphobic site on NTD. Our mAb COV2-3434 did not compete for binding with mAb 5-7 either on SARS-CoV2-6 $\mathrm{P}_{\text {ecto }}$ or on NTD, revealing the COV2-3434 site is unique (Fig. S4).

COV2-3434 exhibits trimer-disrupting properties. To further probe the binding sites for these mAbs, we used negative-stain electron microscopy (nsEM) to image a stabilized trimeric form of the ectodomain of $\mathrm{S}$ protein $\left(\mathrm{S}_{\mathrm{P}}\right.$ ecto trimer) in complex with Fab fragment forms of COV2-3439 or COV2-3434. We chose COV2-3439 as a representative mAb from the first competition group, as it was the most potently neutralizing antibody against VSV-S. COV2-3439 bound to the NTD and recognized the 'closed' conformational state of the $\mathrm{S} 6 \mathrm{P}_{\text {ecto }}$ trimer. We confirmed that the COV2-3439 antibody binds to the previously noted antigenic "supersite" on the NTD of the 
199

200

201

202

203

204

205

206

207

208

209

210

211

212

213

214

215

216

217

218

219

220

221

$\mathrm{S}_{6} \mathrm{P}_{\text {ecto }}$ trimer by overlaying the nsEM maps of the COV2-3439 Fab/S protein complex with our previously published COV2-2676 Fab/S complex (Fig. 4B).

Unexpectedly, we did not observe intact S protein trimers following a one-hour incubation with saturating concentrations of COV2-3434 Fab fragments. Shorter incubation times with Fabs (1, 5 or 30 mins) showed more intact trimers in the grids (Fig. 4C). Representative 2D images revealed that Fabs were bound to the $\mathrm{S}$ protomers, suggesting that Fabs recognize an epitope that is not present or accessible on an intact $\mathrm{S}$ trimer (Fig. 4D). Although the 2D images are revealing, we could not create reconstructions of the Fab-protomers, since there were very limited views of the complexes. The data are consistent with a trimer-disruption mechanism in which binding of the COV2-3434 Fab to a partially occluded epitope drives the disruption of S protein trimer.

We next defined the COV2-3434 and COV2-3439 epitopes at the amino acid level using 2 complementary methods: alanine-scanning loss-of-binding experiments and cell-surface S protein display method. Screening of the NTD alanine-scan library identified primary residues F43, F175, L176 and L226 as critical for binding of COV2-3434 (Fig. 5A), whereas for COV23439 residues R102, Y145, K147, W152, R246, Y248, P251 and G252 were identified (Fig. S5).

None of these single-residue alanine mutants affected binding of the control NTD-reactive mAb COV2-2305 (Fig. 5B). As an alternative approach to learn more about the epitope recognized this trimer-disrupting antibody, we generated complexes of NTD subdomain with Fabs of COV2-3434 and COV2-3439. Intrestingly, in NS-EM we noticed that the COV2-3434 Fab binds NTD at a $90^{\circ}$ angle to that of the supersite-binding COV2-3439 Fab (Fig. 5C). Moreover, when 
222 we overlaid this double Fab + rNTD complex onto that of the trimeric spike complex (7C2L

223 model), COV2-3434 Fab tangentially clashed with interface of RBD and NTD (Fig. 5C).

224 Modeling of double Fab and NTD complexes onto the spike monomer, dimer and trimer when

$225 \mathrm{RBD}$ is open enabled us to locate Fab binding more precisely and suggested that the epitope

226 recognized by COV2-3434 is occluded (Fig. S6). Recently, it was reported that the NTD of

227 SARS-CoV-2 spike binds biliverdin and polysorbate 80 by recruitment of tetrapyrrole rings to

228 evade antibody neutralization. However, our neutralization assays in the presence of biliverdin

229 or polysorbate 80 did not affect COV2-3434 neutralization of VSV-S (Fig. S7), again suggesting

230 this epitope is distinct. Additional structural studies are needed to determine sturcural basis for

231 the trimer-disrupting phenotype of mAbs binding to this epitope.

233 The S protein exhibits high flexibility between domains and can exist in different conformations,

234 allowing the immune system to target distinct epitopes and structural states (Henderson et al.,

235 2020). Henderson et al. showed that conformations of the S protein can be controlled via rational

236 design using expressed soluble ectodomains of the S proteins, in which the three RBDs are either

237 locked in the all-RBDs 'down' position $\left(\mathrm{S}_{\mathrm{P}} \mathrm{ecto}_{\mathrm{e}}-\mathrm{2C}\right)$ or adopt 'up' state $\left(\mathrm{S}_{\mathrm{P}} \mathrm{P}_{\text {ecto }}\right)$ conformations

238 (Henderson et al., 2020). We hypothesized that the COV2-3434 binding site is accessible only

239 when the RBD adopts an 'up' state conformation of $\mathrm{S} 6 \mathrm{P}_{\text {ecto. }}$ To test this model, we quantified

240 binding of COV2-3434 to $\mathrm{S}_{\mathrm{P}} \mathrm{P}_{\text {ecto }}$ or $\mathrm{S}_{\mathrm{P}} \mathrm{P}_{\text {ecto }}-2 \mathrm{C}$ proteins by ELISA. For comparison, we also

241 included a mAb that binds to RBD in either the up or down conformational state (COV2-2130), a

$242 \mathrm{mAb}$ that binds to NTD (COV2-2676), and the negative-control dengue mAb DENV-r2D22. As

243 expected, the binding of $\mathrm{COV} 2-3434$ to $\mathrm{S} 6 \mathrm{P}_{\text {ecto }}-2 \mathrm{C}$ protein was reduced, confirming that the 
244 epitope is cryptic and only accessible when at least one RBD is in its 'up' conformation (Fig.

245 5D).

246

247 SARS-CoV-2 mRNA vaccines can induce trimer-disrupting antibodies. Although we

248 identified a new antigenic site by isolating COV2-3434 from a SARS-CoV-2 convalescent

249 donor, it is uncertain if this class of antibodies forms a major part of the humoral immune

250 response to the $\mathrm{S}$ protein trimer. To address this question, we performed a competition-binding

251 ELISA with serum antibody and COV2-3434. Serum antibodies from each of 4 naturally SARS-

252 CoV-2 infected individuals or from each of 5 individuals before or after SARS-CoV-2 mRNA

253 vaccination were tested. We observed up to $90 \%$ serum antibody competition with COV2-3434

254 in 3 donors tested following vaccination, indicating that in some individuals SARS-CoV-2

255 mRNA vaccination generates high levels of S protein trimer-interface (TI) specific antibodies or

256 antibodies that compete with TI antibodies (Fig. 5E). In contrast, we did not observe this level of

257 competition with COV2-3434 in serum from convalescent donors. Taken together, these results

258 suggest that $\mathrm{S}$ trimer interface antibodies may be more common in the serum of vaccinated than

259 infected individuals. The reason this class of antibodies was observed in the serum of vaccinees

260 but not convalescent individuals is not clear, although engineered vaccine $\mathrm{S}$ antigen differs from

261 the natural S protein in that the "pre-fusion" S conformation was stabilized in the vaccine

262 construct by mutagenesis.

263

264 COV2-3434 inhibits VOC and confers partial protection against SARS-CoV-2 infection.

265 Identification of neutralizing mAbs that bind to distinct antigenic sites on $\mathrm{S}$ proteins might help

266 to avoid escape from neutralization by VOC. To address this idea, we used VSV-S viruses 
267 expressing SARS-CoV-2 S protein variants that were resistant to neutralization by the RBD-

268 specific antibodies COV2-2479, COV2-2499 or COV2-2130 (Greaney et al., 2021) or resistant

269 to the NTD-specific antibodies COV2-2676 and COV2-2489 (Suryadevara et al., 2021). The

270 COV2-3434 mAb neutralized all escape VSV viruses at the higher concentration tested (Fig.

271 6A).

272

273 We next assessed the ability of COV2-3434 to protect K18-hACE2-transgenic mice following

274 viral challenge with SARS-CoV-2 (Golden et al., 2020; Oladunni et al., 2020; Winkler et al.,

275 2021). One day prior to virus inoculation, we passively transferred $\sim 10 \mathrm{mg} / \mathrm{kg}(200 \mu \mathrm{g} / \mathrm{mouse})$ of

276 COV2-2196 (RBD-specific), COV2-3434 (NTD-specific) or DENV-r2D22 (negative control)

277 mAbs. Mice that received r2D22 lost more than 20\% initial body weight. Animals treated with

278 the RBD mAb COV2-2196 were completely protected from weight loss. COV2-3434 conferred

279 intermediate protection against weight loss (Fig. 6B). Pre-treatment with COV2-3434 also

280 partially protected against viral burden, with a 7-fold lower level of infectious virus in the lung

281 compared to the negative-control antibody (Fig 6C). We repeated the study by passively

282 transferring a higher dose (1 mg/mouse) of COV2-2196 (RBD-specific), COV2-3434 (NTD-

283 specific) or DENV-r2D22 (negative control) mAbs, and again saw a comparable reduction of

284 viral titers in the lungs and nasal turbinates (Fig. S8). 


\section{5}

\section{6}

287

288

289

290

291

292

293

294

295

296

297

298

299

300

301

302

303

304

305

306

307

\section{DISCUSSION}

Human neutralizing mAbs to SARS-CoV-2 isolated from recovered COVID-19 individuals are of great importance as potential therapeutic candidates. The continued investigation into identifying protective epitopes using mAbs as we have done here may inform future structurebased rational design of next-generation SARS-CoV-2 vaccines by revealing protective sites whose structure should be preserved in engineered vaccine antigens. Most potently neutralizing SARS-CoV-2 mAbs discovered to date recognize the RBD region, while some moderately neutralizing NTD-directed mAbs also were identified (Barnes et al., 2020; Baum et al., 2020; Cerutti et al., 2021b; Chen et al., 2021b; Chi et al., 2020; Dong et al., 2021; Hansen et al., 2020; McCallum et al., 2021; Pinto et al., 2020; Rogers et al., 2020; Shi et al., 2020; Suryadevara et al., 2021; Turner et al., 2021c; Zost et al., 2020a). All of the NTD-reactive mAbs reported to date have lost their neutralizing capacity against certain emerging VOC. The majority of antibodies identified against NTD target an antigenic site termed the NTD 'supersite' (Cerutti et al., 2021b;

Chi et al., 2020; McCallum et al., 2021; Suryadevara et al., 2021). Although a few other antigenic sites on NTD have been described, mAbs binding to these sites generally were nonneutralizing. The frequent occurrence of mutations in the NTD of multiple circulating SARSCoV-2 variants suggests that the NTD is under strong selective pressure from the host humoral immune response (Weisblum et al., 2020). Furthermore, antigenic changes caused by deletions in NTD have been identified within the antigenic supersite of viruses shed by immunocompromised hosts (Avanzato et al., 2020; Choi et al., 2020; McCarthy et al., 2021).

In this work, we report the isolation and characterization of SARS-CoV-2 neutralizing mAbs targeting the NTD using LIBRA-seq. We used NTD, a domain cloned from the full-length spike, 
as antigen bait for isolating memory B cells from a convalescent donor. More than $90 \%$ of the clones we selected by LIBRA-seq for expression reacted exclusively with NTD, and these subset of eight NTD-targeting antibodies selected by LIBRA-seq was neutralizing. Several of the mAbs potently neutralized VSV-S. The primary target for most of the neutralizing antibodies identified is the NTD 'supersite', as previously described by several groups (Cerutti et al., 2021b; McCallum et al., 2021; Shi et al., 2020; Suryadevara et al., 2021). Most of these NTDsupersite-targeting antibodies appear to be members of a public clonotype. Although diverse public clonotypes recognizing RBD or NTD have been described, we identified an IGHVI-24encoded clonotype that seems to dominate the response to NTD. Clones from this public clonotype are seen following both vaccination and infection.

We also identified an antibody designated COV2-3434 that recognizes a distinct antigenic site on NTD that may represent a new site of vulnerability on SARS-CoV-2 spike. COV2-3434 binds to recombinant SARS-CoV-2 $\mathrm{S}_{\mathrm{P}} \mathrm{P}_{\text {ecto }}$ protein weakly in ELISA, but more avidly to cell-surface-

324 neutralizing antibodies, COV2-3434 weakly inhibits infection of VSV-S and authentic SARS-

325 CoV-2 viruses. With these distinctive phenotypes, we tried to learn more about the mode of 326 recognition of this antigenic site by ns-EM of antigen-antibody complexes. Unexpectedly, we 327 found that COV2-3434 Fab disrupted SARS-CoV-2 S trimers when added to make spike-Fab 328 complexes. This finding of trimer disassociation mediated by COV2-3434 revealed a potential 329 site of vulnerability hidden in the S trimer interface. Similarly, a recently identified NTDreactive neutralizing antibody called 5-7 also recognizes a distinct antigenic site within the NTD, 
331 antibodies of this class insert an antibody hypervariable loop into the exposed hydrophobic

332 pocket between the two sheets of the NTD $\beta$-sandwich (Cerutti et al., 2021a). This pocket was

333 described previously as the binding site for metabolites such as heme with hydrophobic

334 properties (Rosa et al., 2021). Our alanine scan mutagenesis data reveals that COV2-3434 shares

335 some contact residues with mAb 5-7 including F175 and L176, while L226 is barely deeper than

336175 and 176. However, COV2-3434 also lost its binding capacity when deeper pocket residues

337 F43 and was mutated. We noted that in the spike trimer, residue F43 lies at an interface between

338 adjacent monomers such that MAb binding could intiate a destabilization of the trimer.

340 Recently several reports about mAbs targeting the trimer interface of multiple viral antigens have

341 been published. For instance, the non-neutralizing influenza mAbs FluA20 and 5J6 that

342 recognize the hemagglutinin trimer interface (Bangaru et al., 2019; Zost et al., 2021) were

343 identified from influenza-vaccinated individuals. Also, epitope mapping using polyclonal serum

344 from vaccinated rabbits identified antibodies recognizing the HIV envelope glycoprotein trimer 345 interface (Turner et al., 2021a). Similarly, the epitope for a neutralizing mAb for human 346 metapneumovirus (MPV458) lies within the trimeric interface of pneumovirus fusion proteins

347 (Huang et al., 2020).

349 COV2-3434 is a rare SARS-CoV-2 S trimer interface antibody that mediates virus neutralization.

350 Our COV2-3434 competition data suggest that this class of mAbs may be common in the serum 351 of some vaccinated individuals. Hence, surveillance of this class of antibodies and understanding 352 its contribution to vaccine protection is important, particularly in the context of emergence of 
new VOC and updated vaccine designs. While these trimer-interface mAbs do not all neutralize virus in vitro, passive transfer of these mAbs can mitigate severe disease. For example, the FluA20 mAb did not neutralize influenza, but still conferred protection in mice challenged with H1N1 A/California/04/2009 virus (Bangaru et al., 2019). Here, the moderately neutralizing COV2-3434 conferred partial protection against weight loss and lung infection in mice when

358 given as prophylaxis.

In summary, using LIBRA-seq, we identified the mAb COV2-3434 that binds to a distinct antigenic site on the NTD and disassociates S trimers by contacting critical residues in a cryptic hydrophobic pocket in the $\mathrm{S}$ trimer interface.

ACKNOWLEDGEMENTS. We thank Merissa Mayo and Norma Suazo Galeano for human subject's regulatory support. EM data collection was conducted at the Center for Structural Biology Cryo-EM Facility at Vanderbilt University. This work was supported by the NIAID/NIH grants R01 AI157155 (M.S.D. and J.E.C.), R01 AI131722-S1 (I.S.G.), HHSN contracts 75N93019C00074 (J.E.C.) and 75N93019C00073 (B.J.D.), DARPA grant HR0011-18-

370 Mason University (J.E.C. and I.S.G.). J.E.C. is a recipient of the 2019 Future Insight Prize from 371 Merck KGaA. J.B.C. is supported by a Helen Hay Whitney Foundation postdoctoral fellowship.

372 We thank Dr. Jason McLellan for a gift of $\mathrm{S} \mathrm{P}_{\text {ecto }}$ protein used in the LIBRAseq studies.

373 Recombinant SARS-CoV-2 S NTD protein was kindly provided by P. McTamney, K. Ren and

374 A. Barnes (AstraZeneca). The content is solely the responsibility of the authors and does not 375 represent the official views of the U.S. government or other sponsors. 
376 DECLARATION OF INTERESTS. M.S.D. is a consultant for Inbios, Vir Biotechnology,

377 Senda Biosciences, and Carnival Corporation, and is on the Scientific Advisory Boards of

378 Moderna and Immunome. The Diamond laboratory has received unrelated funding support in

379 sponsored research agreements from Vir Biotechnology, Moderna, and Emergent BioSolutions.

380 A.R.S. and I.S.G. are co-founders of AbSeek Bio. The Georgiev laboratory at Vanderbilt

381 University Medical Center has received unrelated funding from Takeda Pharmaceuticals. C.N.S.,

382 E.D., and B.J.D. are employees of Integral Molecular, and B.J.D.is a shareholder in that

383 company. J.E.C. has served as a consultant for Eli Lilly, GlaxoSmithKline and Luna Biologics,

384 is a member of the Scientific Advisory Boards of Meissa Vaccines and is Founder of

385 IDBiologics. The Crowe laboratory at Vanderbilt University Medical Center has received

386 unrelated sponsored research agreements from Takeda, IDBiologics and AstraZeneca.

388 AUTHOR CONTRIBUTIONS. Conceived of the project: N.S., J.E.C.; Obtained funding:

389 M.S.D., I.S.G and J.E.C. Performed laboratory experiments: N.S., A.S., R.E.C., E.B., L.V.B.,

390 J.B.C., K.K., L.M., A.T., S.M.D., L.S.H., R.N., C.N.S., E.D., Supervised research: B.J.D., I.G.,

391 R.H.C., J.E.C. Wrote the first draft of the paper: N.S., J.E.C.; All authors reviewed and approved

392 the final manuscript. 


\section{FIGURE LEGENDS}

395

\section{Figure 1. Characterization of SARS-CoV-2 antibodies in convalescent patient samples.}

397 A. Serum or plasma antibody reactivity for the four SARS-CoV-2 convalescent patients and one non-immune healthy control subject were assessed by ELISA using SARS-CoV-2 S6P $\mathrm{ecto}_{\mathrm{RBD}}$, $\mathrm{S}_{\mathrm{NTD}}$, SARS-CoV S2P $\mathrm{ecto}_{\text {or }}$ PBS. Optical density was measured with a 450-nm filter $\left(\mathrm{OD}_{450}\right)$

400 using a microplate reader. Error bars, s.d.; data are representative of at least two independent experiments performed in technical duplicate.

B. Plasma or serum neutralizing activity against the VSV-S for SARS-CoV-2 convalescent donor 1989 on day 18, 28, 56 or day 90 in an RTCA neutralization assay. Data represent two experiments performed in technical duplicate. C. Plasma 404 or serum neutralizing activity against the WA1/2020 strain SARS-CoV-2 for convalescent donor 4051989 on day 18, 28, 56 or day 90 using a FRNT. Data represent experiments performed in 406 technical duplicate. Data represent two experiments performed in technical duplicate. 
407 Figure 2. Reactivity, functional and genetic features of 102 human mAbs identified using

408 LIBRA-seq.

409 A. LIBRA seq scores for all cells per experiment are shown as black circles from three different

410 LIBRA-seq runs. Antibodies that demonstrated either full and partial neutralization in the high-

411 throughput RTCA assay are highlighted in green or purple, respectively.

412 B. MAb specificity or reactivity for each of four $\mathrm{S}$ proteins or subdomains. The figure shows a

413 heatmap for binding of 102 mAbs expressed recombinantly, representing OD values collected at

$414450 \square \mathrm{nm}$ for each antigen (range, 0.5 to 4.0 ). White indicates a lack of detectable binding, blue

415 indicates binding, and darker blue indicates higher OD values. To the right are the antibody

416 numbers that demonstrated either full or partial neutralization in the high-throughput RTCA

417 assay, highlighted in green or purple, respectively.

418 C. Genetic characteristics for mAbs that demonstrated either full or partial neutralization along

419 with their ELISA reactivity; numbers in the boxes represent OD values collected at $450 \square \mathrm{nm}$

420 (range, 0.5 to 4.0) and LIBRA-seq scores for each antigen. White fill indicates no or low

421 reactivity, red (ELISA) or purple (LIBRA-seq) fill represent reactivity for the respective

422 antigens. 


\section{Figure 3. Activity of neutralizing mAbs against SARS-CoV-2.}

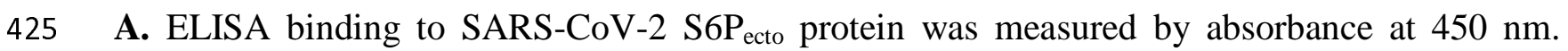

426 Antibody concentrations starting at $20 \mu \mathrm{g} / \mathrm{mL}$ were used and titrated two-fold. Calculated

$427 \mathrm{EC}_{50}$ values are shown on the graph. Error bars indicate standard deviation; data represent at

428 least two independent experiments performed in technical duplicate.

429 B. Binding to the surface of VSV-S-infected Vero cells was measured using flow cytometry and 430 median florescence intensity values were determined for dose-response binding curves. Antibody 431 was diluted 3-fold staring from $20 \mu \mathrm{g} / \mathrm{mL}$. Data represent two experiments performed in 432 technical triplicate.

433 C. VSV-S neutralization curves for mAbs that were expressed after high throughput RTCA 434 neutralization conformation. Calculated $\mathrm{IC}_{50}$ values are shown on the graph. Error bars indicate 435 standard deviation; data represent at least two independent experiments performed in technical 436 duplicate.

437 D. Neutralization curves for COV2-3434 or COV2-2196 against SARS-CoV-2 virus. Calculated $438 \mathrm{IC}_{50}$ values are shown on the graph. Error bars indicate standard deviation; data represent at least 439 two independent experiments performed in technical duplicate.

440 E. Germline-revertant (GR) COV2-3443 antibody reactivity and functional activity, ELISA 441 binding to SARS-CoV-2 S6P $\mathrm{P}_{\text {ecto }}$ protein was measured by absorbance at $450 \mathrm{~nm}$ and binding to 442 the surface of VSV-S-infected Vero cells was measured using flow cytometry and median 443 florescence intensity values were determined for dose response binding curves. 
bioRxiv preprint doi: https://doi.org/10.1101/2022.01.12.476120; this version posted January 13,2022 . The copyright holder for this preprint (which was not certified by peer review) is the author/funder, who has granted bioRxiv a license to display the preprint in perpetuity. It is made available under aCC-BY-NC-ND 4.0 International license.

444 F. VSV-S neutralization curves for germline-revertant COV2-3443 antibody. Error bars indicate

445 standard deviation; data represent at least two independent experiments performed in technical

446 duplicate.

447 

3434 antibodies.

A. Competition of the panel of neutralizing mAbs with previously mapped antibodies COV2-

to antigen first are indicated on the left, while biotinylated antibodies that were added to antigencoated wells second are listed across the top. The number in each box represents the percent competition binding of the biotinylated antibody in the presence of the indicated competing antibody. Heat map colors range from dark grey (100\% binding of the biotinylated antibody) to white ( $0 \%$ or no binding of the biotinylated antibody). The experiment was performed in

457 biological replicate. Biological replicate from representative single experiment shown. view and top view of superimposed 3D volume COV2-3439 Fab-S6 $\mathrm{P}_{\text {ecto }}$ closed trimer (S protein model PDB:7JJI) complexes as visualized by negative-stain EM for COV2-2676 Fab model in gold, COV2-2489 Fab model in grey. At the bottom, negative-stain 2D classes of SARS-CoV-2 collection statistics are provided in Supplementary Table 3. was added to SARS-CoV-2 $\mathrm{S}_{\mathrm{P}} \mathrm{P}_{\text {ecto }}$ trimer, incubated for 1, 5, 30 mins or $1 \mathrm{hr}$ and placed on an nsEM grid. 
A. Residues identified as important for COV2-3434 binding are highlighted as spheres on the S

471 protein structure (green ribbon; PDB 7L2C) F43 (magenta), F175, L176 (cyan), or L226

472 (orange). Residues critical for COV2-3434 binding were identified from binding screens of an

473 alanine scanning mutagenesis library of NTD.

474

B. MAb binding values for COV2-3434, COV2-3439, and control anti-NTD mAb COV2-2305

475 are shown at SARS-CoV-2 $\mathrm{S}$ protein clones identified as critical for MAb binding. MAb

476 reactivities for each mutant are expressed as percent of binding to wild-type $\mathrm{S}$ protein, with

477 ranges (half of the maximum minus minimum values). Two replicate values were obtained for

478 each experiment.

C. Negative-stain EM of SARS-CoV-2 rNTD protein in complex with COV2-3439 and COV23434 Fabs. Top view and side view of superimposed 3D volume COV2-3434 Fab - COV2-3439

Fab - SARS-CoV-2 rNTD complexes as visualized by negative-stain EM aligned to S protein of SARS-CoV-2 in complex with 4A8 (PDB: 7C2L) Data are from a single experiment; detailed collection statistics are provided in Supplementary Table 3.

D. ELISA binding to SARS-CoV-2 S6P ecto or SARS-CoV-2 S6P-2C was measured by absorbance at $450 \mathrm{~nm}$. The COV2-2130 starting concentration was $200 \mathrm{ng} / \mathrm{mL}$, the COV2-2676 486 and COV2-3434 starting concentrations were $20 \mu \mathrm{g} / \mathrm{mL}$, and mAbs were titrated two-fold. 487 Calculated $\mathrm{EC}_{50}$ values are shown on the graph. Error bars indicate standard deviation; data 488 represent at least two independent experiments performed in technical duplicate.

489 E. Measurement of serum antibody competition with trimer interface antibody COV2-3434 in 490 individuals before or after SARS-CoV-2 mRNA vaccination. Competition-binding ELISA 
491 curves for COV2-3434 with human serum from convalescent or vaccinated donors. Competition-

492 binding experiments were performed for each sample in triplicate and repeated in at least 2

493 independent experiments. One representative experiment is shown. For all competition-binding

494 curves, data points indicate the mean and error bars indicate the standard deviation. 
Figure 6. Escape virus neutralization and protection in K18 hACE2 transgenic mice by trimer-disrupting antibody COV2-3434.

497

A. Neutralization of mAb escape viruses selected by RBD-specific mAbs COV2-2479 (red), COV2-2130 (green), COV2-2094 (magenta) or COV2-2499 (purple) and NTD-specific mAbs COV2-2676 (blue) or COV2-2489 (cyan) and with VSV-S by COV2-3434 or COV2-2196

500 (positive control). Mutations selected by those mAbs are listed with the references. Toward the 501 right, the RTCA curves show neutralization of those escape viruses, The ${ }^{*}$ symbol indicates lack 502 of neutralization in wells with only virus and no antibody.

B. Eight-week-old male K18-hACE2 transgenic mice were inoculated by the intranasal route 504 with $10^{4}$ FFU of SARS-CoV-2 (WA1/2020 D614G). One day prior to virus inoculation, mice were given a single $200 \mu \mathrm{g}(\sim 10 \mathrm{mg} / \mathrm{kg})$ dose of COV2-3434 or COV2-2196 by intraperitoneal 506 injection. Weight change was monitored daily. Data are from two independent experiments, $507 \mathrm{n}=10$ per group. ${ }^{* *}, \mathrm{p}<0.01 ; * * * *, \mathrm{p}<0.0001$. Error bars represent SEM. per group. ${ }^{* *}, \mathrm{p}<0.01 ; * * * *, \mathrm{p}<0.0001$. 


\section{RESOURCE AVAILABILITY}

LEAD CONTACT. Further information and requests for resources and reagents should be

MATERIALS AVAILABILITY. Materials described in this paper are available for

523 distribution for nonprofit use using templated documents from Association of University

524 Technology Managers “Toolkit MTAs", available at: https://autm.net/surveys-and-

525 tools/agreements/material-transfer-agreements/mta-toolkit.

526

527 DATA AND CODE AVAILABILITY. All data needed to evaluate the conclusions in the paper

528 are present in the paper or the Supplemental Information. The antibodies in this study are

529 available by Material Transfer Agreement with Vanderbilt University Medical Center.

\section{EXPERIMENTAL MODEL AND SUBJECT DETAILS}

532 Research participants. We studied the peripheral blood B cells from four individuals with a

533 history of laboratory-confirmed symptomatic SARS-CoV-2 infection. The study was approved by the Institutional Review Board of Vanderbilt University Medical Center and specimens were

535 obtained after written informed consent. 
537 Cell lines. Vero (ATCC, CCL-81), HEK293 (ATCC, CRL-1573) and HEK293T (ATCC, CRL-

538 3216) cells were maintained at $37^{\circ} \mathrm{C}$ in $5 \% \mathrm{CO} 2$ in Dulbecco's minimal essential medium 539 (DMEM) containing 10\% (v/v) heat-inactivated fetal bovine serum (FBS), 10 $\square \mathrm{mM}$ HEPES pH

$5407.3,1 \square \mathrm{mM}$ sodium pyruvate, $1 \times$ non-essential amino acids and $100 \square \mathrm{U} / \mathrm{mL}$ of penicillin541 streptomycin. Vero-furin cells were obtained from T. Pierson (NIAID, NIH) and have been

542 described previously (45) Vero-hACE2-TMPRSS2 cells were a gift of A. Creanga and B.

543 Graham (Vaccine Research Center, NIH). FreeStyle 293F cells (Thermo Fisher Scientific, 544 R79007) were maintained at $37^{\circ} \mathrm{C}$ in $8 \% \mathrm{CO}$. Expi293F cells (Thermo Fisher Scientific, $545 \mathrm{~A} 1452$ ) were maintained at $37^{\circ} \mathrm{C}$ in $8 \% \mathrm{CO} 2$ in Expi293F Expression Medium (Thermo Fisher 546 Scientific, A1435102). ExpiCHO cells (Thermo Fisher Scientific, A29127) were maintained at $54737^{\circ} \mathrm{C}$ in $8 \% \mathrm{CO} 2$ in ExpiCHO Expression Medium (Thermo Fisher Scientific, A2910002). 548 Mycoplasma testing of Expi293F and ExpiCHO cultures was performed monthly using a PCR549 based mycoplasma detection kit (ATCC, 30-1012K).

Antigen purification. A variety of recombinant soluble protein antigens were used in the 552 LIBRA-seq experiment and other experimental assays. For the LIBRA-seq experiment, we used 553 the S6Pecto construct. This plasmid encoded residues 1-1,208 of the SARS-CoV-2 S protein 554 with a mutated S1/S2 cleavage site, proline substitutions at positions 817, 892, 899, 942, 986 and 555 987, and a C-terminal T4-fibritin trimerization motif, an 8x HisTag, and a TwinStrepTag (SARS556 CoV-2 spike HP). DNA encoding this construct was transiently transfected with PEI in 557 Expi293F cells and after six days of expression, supernatants were harvested, and protein was 
558 affinity-purified over a StrepTrap HP column (Cytiva Life Sciences). Protein was further

559 resolved to homogeneity over a Superose 6 Increase column (GE Life Sciences).

561 We generated a plasmid containing a synthesized cDNA encoding a protein designate SARS -

562 CoV-2 S-2P that possessed residues 1-1,208 of the SARS-CoV-2 spike protein as described

563 ((Wrapp et al., 2020)46) with a mutated S1/S2 cleavage site, proline substitutions at amino acid

564 positions 986 and 987, a C-terminal T4-fibritin trimerization motif, an 8x HisTag, and a

565 TwinStrepTag. The plasmids were transiently transfected into FreeStyle 293F cells (Thermo

566 Fisher Scientific) using polyethylenimine. The design of the two-proline (2P) forms of the

567 coronavirus trimer spike antigens results in a prefusion-stabilized conformation that better

568 represents neutralization-sensitive epitopes in comparison to their wild-type forms. Two $h$ after

569 transfection, cells were treated with kifunensine to ensure uniform glycosylation. Transfected 570 supernatants were harvested after 6 days of expression.

571 SARS-CoV-2 S1 (cat. no: 40591-V08B1), SARS-CoV-2 S2 (cat. no: 40590-V08B), SARS-CoV-

5722 RBD (cat. no: 40592-V05H) and SARS-CoV-2 NTD (cat. no: 40591-V41H-B-20) truncated

573 proteins were purchased (Sino Biological).

575 A gene encoding the ectodomain of a pre-fusion conformation-stabilized SARS-CoV-2 S protein

576 ectodomain (S6Pecto) (Hsieh et al., 2020) was synthesized and cloned into a DNA plasmid

577 expression vector for mammalian cells. A similarly designed S protein antigen with two prolines

578 and removal of the furin cleavage site for stabilization of the prefusion form of S (S2Pecto) was

579 reported previously (Wrapp et al., 2020). In brief, this gene includes the ectodomain of SARS- 
580

581

582

583

584

585

586

587

588

589

590

591

592

593

594

595

596

597

598

599

600

601

602

CoV-2 (to residue 1,208), a T4 fibritin trimerization domain, an AviTag site-specific biotinylation sequence and a C-terminal $8 \times$ His tag. To stabilize the construct in the pre-fusion conformation, we included substitutions F817P, A892P, A899P, A942P, K986P and V987P and mutated the furin cleavage site at residues 682-685 from RRAR to ASVG. The recombinant S6Pecto protein was isolated by metal affinity chromatography on HisTrap Excel columns (Cytiva), and protein preparations were purified further by size-exclusion chromatography on a Superose 6 Increase 10/300 column (Cytiva). The presence of trimeric, pre-fusion conformation S protein was verified by negative-stain electron microscopy (Zost et al., 2020b). For electron microscopy with S protein and Fabs, we expressed a variant of S6Pecto lacking an AviTag but containing a C-terminal Twin-Strep-tag, similar to that described previously (Zost et al., 2020b). Expressed protein was isolated by metal affinity chromatography on HisTrap Excel columns (Cytiva), followed by further purification on a StrepTrap HP column (Cytiva) and size-exclusion chromatography on TSKgel G4000SWXL (TOSOH).

Mouse models. Animal studies were carried out in accordance with the recommendations in the Guide for the Care and Use of Laboratory Animals of the National Institutes of Health. The protocols were approved by the Institutional Animal Care and Use Committee at the Washington University School of Medicine (assurance number A3381-01). Virus inoculations were performed under anesthesia that was induced and maintained with ketamine hydrochloride and xylazine, and all efforts were made to minimize animal suffering. Heterozygous K18-hACE c57BL/6J mice (strain: 2B6.Cg-Tg(K18-ACE2)2Prlmn/J) were obtained from Jackson Laboratory (034860). Eight to nine week-old mice of both sexes were inoculated with 103 PFU of SARS-CoV-2 by an intranasal route. 
We used oligonucleotides that possess a 15-basepair antigen barcode, a sequence capable of

Ns represent the antigen barcode as previously described (Setliff et al., 2019). For each antigen, a unique DNA barcode was directly conjugated to the antigen itself. In particular, 5'amino-

612 oligonucleotides were conjugated directly to each antigen using the SoluLINK Protein-

613 Oligonucleotide Conjugation Kit (TriLink cat. no. S-9011) according to manufacturer's

614 instructions. Briefly, the oligonucleotide and protein were desalted, and then the amino-oligo 615 was modified with the 4FB crosslinker, and the biotinylated antigen protein was modified with 616 S-HyNic. Then, the 4FB-oligo and the HyNic-antigen were mixed. This action causes a stable 617 bond to form between the protein and the oligonucleotide. The concentration of the antigen-oligo 618 conjugates was determined by a BCA assay, and the HyNic molar substitution ratio of the 619 antigen-oligo conjugates was analyzed using a NanoDrop instrument according to the SoluLINK 620 protocol guidelines. Chromatography separation on an AKTA FPLC instrument was used to

621 remove excess oligonucleotide from the protein-oligo conjugates, which were also verified using 622 SDS-PAGE with a silver stain. Antigen-oligo conjugates also were used in flow cytometry 623 titration experiments. 
625

626

627

628

629

630

631

632

633

634

635

636

637

638

639

640

641

642

643

644

645

646

\section{METHOD DETAILS}

Antigen-specific B cell sorting. Cells were stained and mixed with DNA-barcoded antigens and other antibodies, and then sorted using fluorescence activated cell sorting (FACS). First, cells were counted, and viability was assessed using Trypan Blue. Then, cells were washed three times with DPBS supplemented with $0.1 \%$ bovine serum albumin (BSA). Cells were resuspended in DPBS-BSA and stained with cell markers including viability dye (Ghost Red 780), CD14-APC-Cy7, CD3-FITC, CD19-BV711, and IgG-PE-Cy5. Additionally, antigen-oligo conjugates were added to the stain. After staining in the dark for $30 \mathrm{~min}$ at room temperature, cells were washed three times with DPBS-BSA at $300 \mathrm{x} \mathrm{g}$ for five min. Cells then were incubated for $15 \mathrm{~min}$ at room temperature with Streptavidin-PE to label cells with bound antigen. Cells were washed three times with DPBS-BSA, resuspended in DPBS, and sorted by FACS. Antigen-positive cells were bulk sorted and delivered to the Vanderbilt Technologies for Advanced Genomics (VANTAGE) sequencing core laboratory at an appropriate target concentration for 10X Genomics library preparation and subsequent sequence analysis. FACS data were analyzed using FlowJo ${ }^{\mathrm{TM}}$ Software (Mac) version 10.6 (Becton, Dickinson).

Sample preparation, library preparation, and sequencing. Single-cell suspensions were loaded onto a Chromium Controller microfluidics device (10X Genomics) and processed using the B-cell Single Cell V(D)J solution according to manufacturer's suggestions for a target capture of $10,000 \mathrm{~B}$ cells per $1 / 810 \mathrm{X}$ cassette, with minor modifications to intercept, amplify and purify the antigen barcode libraries as previously described (Setliff et al., 2019). 
647 Sequence processing and bioinformatic analysis. We used our previously described pipeline to

648 use paired-end FASTQ files of oligo libraries as input, process and annotate reads for cell

649 barcode, UMI, and antigen barcode, and generate a cell barcode - antigen barcode UMI count

650 matrix ((Setliff et al., 2019; Shiakolas et al., 2021). BCR contigs were processed using Cell

651 Ranger software (10X Genomics) using GRCh38 as reference. Antigen barcode libraries were

652 also processed using Cell Ranger. The overlapping cell barcodes between the two libraries were

653 used as the basis of the subsequent analysis. We removed cell barcodes that had only non-

654 functional heavy chain sequences and cells with multiple functional heavy chain sequences

655 and/or multiple functional light chain sequences, reasoning that these may be multiplets.

656 Additionally, we aligned the BCR contigs (filtered_contigs.fasta file output by Cell Ranger, 10X

657 Genomics) to IMGT reference genes using HighV-Quest (Alamyar et al., 2012). The output of 658 HighV-Quest was parsed using ChangeO (Gupta et al., 2015) and merged with an antigen 659 barcode UMI count matrix. Finally, we determined the LIBRA-seq score for each antigen in the 660 library for every cell as previously described (Setliff et al., 2019).

High-throughput antibody expression. For high-throughput production of recombinant antibodies, approaches were used that are designated as microscale. For antibody expression, microscale transfections were performed $(\sim 1 \square \mathrm{mL}$ per antibody) of Chinese hamster ovary

665 (CHO) cell cultures using the Gibco ExpiCHO Expression System and a protocol for deep 96well blocks (Thermo Fisher Scientific). In brief, synthesized antibody-encoding DNA ( 2 $\square \mu \mathrm{g}$

667 per transfection) was added to OptiPro serum free medium (OptiPro SFM), incubated with 668 ExpiFectamine CHO Reagent and added to $800 \square \mu \mathrm{L}$ of ExpiCHO cell cultures into 96-deep-well 669 blocks using a ViaFlo 384 liquid handler (Integra Biosciences). The plates were incubated on an 
670 orbital shaker at $1,000 \square$ r.p.m. with an orbital diameter of $3 \square \mathrm{mm}$ at $37^{\circ} \mathrm{C}$ in $8 \% \mathrm{CO} 2$. The day

671 after transfection, ExpiFectamine CHO Enhancer and ExpiCHO Feed reagents (Thermo Fisher

672 Scientific) were added to the cells, followed by $4 \square \mathrm{d}$ incubation for a total of $5 \square \mathrm{d}$ at $37^{\circ} \mathrm{C}$ in $8 \%$

$673 \mathrm{CO}$. Culture supernatants were collected after centrifuging the blocks at $450 \mathrm{x} \mathrm{g}$ for $5 \square \mathrm{min}$ and

674 were stored at $4^{\circ} \mathrm{C}$ until use. For high-throughput microscale antibody purification, fritted deep-

675 well plates were used containing $25 \square \mu \mathrm{L}$ of settled protein G resin (GE Healthcare Life Sciences)

676 per well. Clarified culture supernatants were incubated with protein $\mathrm{G}$ resin for antibody

677 capturing, washed with PBS using a 96-well plate manifold base (Qiagen) connected to the

678 vacuum and eluted into 96-well PCR plates using $86 \square \mu \mathrm{L}$ of $0.1 \square \mathrm{M}$ glycine-HCL buffer

$679 \mathrm{pH} \square$ 2.7. After neutralization with $14 \square \mu \mathrm{L}$ of $1 \square \mathrm{M}$ Tris-HCl $\mathrm{pH} \square$ 8.0, purified antibodies were

680 buffer-exchanged into PBS using Zeba Spin Desalting Plates (Thermo Fisher Scientific) and 681 stored at $4^{\circ} \mathrm{C}$ until use.

682

MAb production and purification. cDNAs encoding mAbs of interest were synthesized (Twist Bioscience) and cloned into an IgG1 monocistronic expression vector (designated as pTwistmCis_G1) or Fab expression vector (designated as pTwist-mCis_FAB) and used for production

686 in mammalian cell culture. This vector contains an enhanced 2A sequence and GSG linker that 687 allows for the simultaneous expression of mAb heavy and light chain genes from a single 688 construct upon transfection (Chng et al., 2015). For antibody production, we performed 689 transfection of ExpiCHO cell cultures using the Gibco ExpiCHO Expression System as

690 described by the vendor. IgG molecules were purified from culture supernatants using HiTrap 691 MabSelect SuRe (Cytiva) on a 24-column parallel protein chromatography system (Protein 692 BioSolutions). 
694 Fab proteins were purified using CaptureSelect column (Thermo Fisher Scientific). Purified 695 antibodies were buffer-exchanged into PBS, concentrated using Amicon Ultra-4 50-kDa (IgG) or $30 \mathrm{kDa}(\mathrm{Fab})$ centrifugal filter units (Millipore Sigma) and stored at $4^{\circ} \mathrm{C}$ until use. $\mathrm{F}(\mathrm{ab} \phi) 2$

697 fragments were generated after cleavage of IgG with IdeS protease (Promega) and then purified using TALON metal affinity resin (Takara) to remove the enzyme and protein A agarose (Pierce) MCS instrument (Charles River).

ELISA binding assays. Wells of 96-well microtiter plates were coated with purified $4 \square{ }^{\circ} \mathrm{C}$ overnight. Plates were blocked with $2 \%$ non-fat dry milk and $2 \%$ normal goat serum in Dulbecco's phosphate-buffered saline (DPBS) containing 0.05\% Tween-20 (DPBS-T) for $1 \mathrm{~h}$.

708 The bound antibodies were detected using goat anti-human IgG conjugated with horseradish peroxidase (HRP) (Southern Biotech, cat. 2040-05, lot B3919-XD29, 1:5,000 dilution) and a 3,3',5,5'-tetramethylbenzidine (TMB) substrate (Thermo Fisher Scientific). Color development was monitored, $1 \mathrm{M} \mathrm{HCl}$ was added to stop the reaction, and the absorbance was measured at $712450 \mathrm{~nm}$ using a spectrophotometer (Biotek). For dose-response assays, serial dilutions of 713 purified mAbs were applied to the wells in triplicate, and antibody binding was detected as 714 detailed above. Half maximal effective concentration $\left(\mathrm{EC}_{50}\right)$ values for binding were determined 
715

716

717

718

719

720

721

722

723

724

725

726

727

728

729

730

731

732

733

734

735

736

using Prism v.8.0 software (GraphPad) after log transformation of the mAb concentration using sigmoidal dose-response nonlinear regression analysis.

Cell-surface antigen-display assay. Vero cell monolayers were monitored until $80 \%$ confluent and then inoculated with VSV-SARS-CoV-2 virus (Wa1/2020 strain) (designated here as VSVS) at an MOI of 0.5 in culture medium (DMEM with 2\% FBS). For a T-225 flask, $10 \mathrm{~mL}$ of diluted VSV-S virus was added to the monolayer, then incubated for $40 \mathrm{~min}$. During the incubation, the flask was gently rocked back and forth every 10 min to ensure even infection. Following, the incubation the flask volume was topped off to $30 \mathrm{~mL}$ with $2 \%$ FBS containing DMEM and incubated for $14 \mathrm{~h}$. Cells were monitored for CPE under a microscope, were trypsinized and washed in FACS buffer. 100,000 infected cells were seeded per well to stain with respective antibodies. All antibody was diluted to $10 \mu \mathrm{g} / \mathrm{mL}$ in FACS buffer, and then serially diluted 3-fold 7 times to stain for antibodies that react to cell-surface-displayed S protein. Infected cells then were resuspended in $50 \mu \mathrm{L}$ of diluted antibody. Antibody binding was detected with anti-IgG Alexa-Fluor-647-labelled secondary antibodies. Cells were analyzed on an iQue cytometer for staining first by gating to identify infected cells as indicated by GFPpositive cells, and then gated for secondary antibody binding.

Focus reduction neutralization test (FRNT). Serial dilutions of serum/plasma were incubated with $102 \mathrm{FFU}$ of SARS-CoV-2 for $1 \mathrm{~h}$ at $37^{\circ} \mathrm{C}$. The antibody-virus complexes were added to Vero E6 cell-culture monolayers in 96 -well plates for $1 \mathrm{~h}$ at $37^{\circ} \mathrm{C}$. Cells then were overlaid with $1 \%(\mathrm{w} / \mathrm{v})$ methylcellulose in minimum essential medium (MEM) supplemented to contain $2 \%$ 
737 heat-inactivated FBS. Plates were fixed $30 \mathrm{~h}$ later by removing overlays and fixed with $4 \%$

738 paraformaldehyde (PFA) in PBS for $20 \mathrm{~min}$ at room temperature. The plates were incubated

739 sequentially with $1 \mu \mathrm{g} / \mathrm{mL}$ of rCR3022 anti-S antibody or a murine anti-SARS-CoV-2 mAb,

740 SARS2-16 (hybridoma supernatant diluted 1:6,000 to a final concentration of $\sim 20 \mathrm{ng} / \mathrm{mL}$ ) and

741 then HRP-conjugated goat anti-human IgG (Sigma-Aldrich, A6029) in PBS supplemented with

$7420.1 \%(\mathrm{w} / \mathrm{v})$ saponin (Sigma) and 0.1\% BSA. SARS-CoV-2-infected cell foci were visualized

743 using TrueBlue peroxidase substrate (KPL) and quantitated on an ImmunoSpot 5.0.37 Macro

744 Analyzer (Cellular Technologies). Half maximal inhibitory concentration $\left(\mathrm{IC}_{50}\right)$ values were

745 determined by nonlinear regression analysis (with a variable slope) using Prism software.

High-throughput real-time cell analysis (RTCA) neutralization assay. To screen for

748

749

750

751

752

753

754

755

756

757

758

759

neutralizing activity in the panel of recombinantly expressed mAbs, we used a high-throughput and quantitative RTCA assay and xCelligence RTCA HT Analyzer (ACEA Biosciences) that assesses kinetic changes in cell physiology, including virus-induced cytopathic effect (CPE). Twenty $\mu \mathrm{L}$ of cell culture medium (DMEM supplemented with $2 \%$ FBS) was added to each well of a 384-well E-plate using a ViaFlo384 liquid handler (Integra Biosciences) to obtain background reading. Six thousand $(6,000)$ Vero-furin cells in $20 \square \mu \mathrm{L}$ of cell culture medium were seeded per well, and the plate was placed on the analyzer. Sensograms were visualized using RTCA HT software version 1.0.1 (ACEA Biosciences). For a screening neutralization assay, equal amounts of virus were mixed with micro-scale purified antibodies in a total volume of $40 \square \mu \mathrm{L}$ using DMEM supplemented with $2 \% \mathrm{FBS}$ as a diluent and incubated for $1 \square \mathrm{h}$ at $37^{\circ} \mathrm{C}$ in $5 \% \square \mathrm{CO} 2$. At $\sim 17-20 \square \mathrm{h}$ after seeding the cells, the virus-mAb mixtures were added to the cells in 384-well E-plates. Wells containing virus only (in the absence of mAb) and wells 
760

761

762

763

764

765

766

767

768

769

770

771

772

773

774

775

776

777

778

779

780

781

782

containing only Vero cells in medium were included as controls. Plates were measured every 8$12 \mathrm{~h}$ for $48-72 \mathrm{~h}$ to assess virus neutralization. Micro-scale antibodies were assessed in four 5fold dilutions (starting from a 1:20 sample dilution), and their concentrations were not normalized. In some experiments, mAbs were tested in triplicate using a single (1:20) dilution. Neutralization was calculated as the percent of maximal cell index in control wells without virus minus cell index in control (virus-only) wells that exhibited maximal CPE at 40 to $48 \mathrm{~h}$ after applying virus-antibody mixture to the cells. A mAb was classified as fully neutralizing if it completely inhibited SARS-CoV-2-induced CPE at the highest tested concentration, while a $\mathrm{mAb}$ was classified as partially neutralizing if it delayed but did not fully prevent CPE at the highest tested concentration.

Conventional throughput neutralization assay. To determine neutralizing activity of serum/plasma and IgG, we used real-time cell analysis (RTCA) assay on an xCELLigence RTCA MP Analyzer (ACEA Biosciences Inc.) that measures virus-induced cytopathic effect (CPE) (Gilchuk et al., 2020; Zost et al., 2020b). Briefly, $50 \mu \mathrm{L}$ of cell culture medium (DMEM supplemented with 2\% FBS) was added to each well of a 96-well E-plate using a ViaFlo384 liquid handler (Integra Biosciences) to obtain background reading. A suspension of 18,000 VeroE6 cells in $50 \mu \mathrm{L}$ of cell culture medium was seeded in each well, and the plate was placed on the analyzer. Measurements were taken automatically every $15 \mathrm{~min}$, and the sensograms were visualized using RTCA software version 2.1.0 (ACEA Biosciences Inc). VSV-S (0.01 MOI, 120 PFU per well) was mixed 1:1 with a dilution of serum/plasma or mAb in a total volume of $100 \mu \mathrm{L}$ using DMEM supplemented with $2 \% \mathrm{FBS}$ as a diluent and incubated for $1 \mathrm{~h}$ at $37^{\circ} \mathrm{C}$ in $5 \% \mathrm{CO} 2$. At $16 \mathrm{~h}$ after seeding the cells, the virus-mAb mixtures were added in replicates to the 
783

784

785

786

787

788

789

790

791

792

793

794

795

796

797

798

799

800

801

802

803

804

805

cells in 96-well E-plates. For the biliverdin assay, biliverdin was added to the virus at a final concentration of $25 \mu \mathrm{M}$ before addition to the antibody; similarly, polysorbate- 80 was added to the virus at $0.02 \%$ before addition to the antibody. Triplicate wells containing virus only (maximal $\mathrm{CPE}$ in the absence of $\mathrm{mAb}$ ) and wells containing only Vero cells in medium (no-CPE wells) were included as controls. Plates were measured continuously (every $15 \mathrm{~min}$ ) for $48 \mathrm{~h}$ to assess virus neutralization. Normalized cellular index (CI) values at the endpoint (48 $\mathrm{h}$ after incubation with the virus) were determined using the RTCA software version 2.1.0 (ACEA Biosciences Inc.). Results are expressed as percent neutralization in a presence of respective $\mathrm{mAb}$ relative to control wells with no $\mathrm{CPE}$ minus $\mathrm{CI}$ values from control wells with maximum CPE. RTCA IC50 values were determined by nonlinear regression analysis using Prism software.

Electron microscopy sample and grid preparation, imaging and processing of S6Pecto-Fab complexes. For electron microscopy imaging of spike protein and Fabs, we expressed a variant of S6Pecto containing a C-terminal Twin-Strep-tag, similar to that described previously (Zost et al., 2020b). Expressed protein was incubate with BioLock (IBA Lifesciences) and then isolated by Strep affinity chromatography on StrepTrap HP columns (GE Healthcare). Fabs were expressed as a recombinant Fab and purify with affinity column. For screening and imaging of negatively-stained SARS-CoV-2 S6Pecto protein in complex with human Fabs, the proteins were incubated at a Fab:spike molar ratio of 4:1 for about 1 hour at ambient temperature or overnight at $4{ }^{\circ} \mathrm{C}$, and approximately $3 \mu \mathrm{L}$ of the sample at concentrations of about 10 to $15 \mu \mathrm{g} / \mathrm{mL}$ was applied to a glow-discharged grid with continuous carbon film on 400 square mesh copper electron microscopy grids (Electron Microscopy Sciences). The grids were stained with $0.75 \%$ 
uranyl formate (Ohi et al., 2004). Images were recorded on a Gatan US4000 4k×4k CCD camera using an FEI TF20 (TFS) transmission electron microscope operated at $200 \mathrm{keV}$ and control with Serial EM (Mastronarde, 2005). All images were taken at 50,000× magnification with a pixel size of $2.18 \AA$ per pixel in low-dose mode at a defocus of $1.5-1.8 \mu \mathrm{m}$. The total dose for the micrographs was around 30e-per Å2. Image processing was performed using the cryoSPARC (Punjani et al., 2017) software package. Images were imported, CTF-estimated and particles were picked. The particles were extracted with a box size of 256 pixels and binned to 128 pixels (pixel size of $4.36 \mathrm{~A} / \mathrm{pix}$ ) and 2D class averages were performed (see also Supplementary Table 3 for detailed). For time point of the complex with Fab Cov2-3434, SARS-CoV-2 S6Pecto protein and the Fab was mixed at ambient temperature and samples of $\sim 3 \mu \mathrm{L}$ were pulled at the time points and applied to the grid and stained.

\section{Serum antibody competition binding ELISAs with biotinylated reference mAbs. $\mathrm{mAb}$} COV2-3434 was biotinylated using NHS-PEG4-biotin (Thermo Fisher Scientific, cat\# A39259) according to manufacturer protocol. Following biotinylation, biotinylated COV2-3434 was titrated in ELISA to verify specific binding and verify if EC50 was similar to the un-biotinylated antibody. Serum samples for use in competition ELISA were heat inactivated by incubation at $55^{\circ} \mathrm{C}$ for $1 \mathrm{hr}$. ELISAs were performed using 384-well plates that were coated overnight at 1 $\mu \mathrm{g} / \mathrm{mL}$ with S6Pecto containing a C-terminal Twin-Strep-tag, similar to that described previously (Zost et al., 2020b). The following day, plates were washed three times with PBS-T and blocked with $2 \%$ bovine serum albumin (BSA) in PBS containing $0.05 \%$ Tween-20 (blocking buffer). Plates were washed three times with PBS-T and two-fold serial dilutions of donor serum (1:10 initial dilution) or control $\mathrm{mAb}(20,000 \mathrm{ng} / \mathrm{mL}$ initial dilution) in blocking 
829

830

831

832

833

834

835

836

837

838

839

840

841

842

843

844

845

846

847

848

849

850

851

buffer were added to each plate (total volume $25 \mu \mathrm{L} /$ well) and incubated at RT for $1 \mathrm{hr}$. After incubation, $5 \mu \mathrm{L}$ of biotinylated COV2-3434 (20 $\mu \mathrm{g} / \mathrm{mL})$ in blocking buffer were added directly

to the wells containing the serial dilutions of competing serum or COV2-3434 mAb. The concentration of biotinylated $\mathrm{mAb}$ was calculated to be at approximately the EC90 of the mAb after addition to an equal volume of competing serum or mAb in the plate. Plates were incubated for $30 \mathrm{~min}$ at RT and then washed three times with PBS-T. After this wash, HRP-conjugated avidin (Sigma Aldrich, 1:3,500 dilution) in blocking buffer was added and plates were incubated for $1 \mathrm{~h}$. After incubation, plates were washed three times with PBS-T and $25 \mu \mathrm{L}$ of a 3,3',5,5'tetramethylbenzidine (TMB) substrate (Thermo Fisher Scientific) was added to each well. After sufficient development, the reaction was quenched by addition of $25 \mu \mathrm{L} 1 \mathrm{M} \mathrm{HCl}$ and the optical density values were measured at $450 \mathrm{~nm}$ wavelength on a BioTek plate reader. For each plate, background signal (signal from wells that were not coated with antigen) was subtracted and values were normalized to no-competition controls (signal from wells that had no competing serum or $\mathrm{mAb}$ ) Four-parameter dose-response/inhibition curves were fit to the normalized data using Prism software (GraphPad) v8.1.1. Each dilution of serum or mAb was performed in triplicate and each experiment was conducted at least twice independently.

Protection against SARS-CoV-2 in mice. Animal studies were carried out in accordance with the recommendations in the Guide for the Care and Use of Laboratory Animals of the National Institutes of Health. The protocols were approved by the Institutional Animal Care and Use Committee at the Washington University School of Medicine (Assurance number A3381-01). Virus inoculations were performed under anesthesia that was induced and maintained with ketamine hydrochloride and xylazine, and all efforts were made to minimize animal suffering. 
853 Female heterozygous K18-hACE C57BL/6J mice were housed in groups of up to 5 mice per

854 cage at 18 to $24^{\circ} \mathrm{C}$ ambient temperatures and 40 to $60 \%$ humidity. Mice were fed a $20 \%$ protein 855 diet (PicoLab 5053, Purina) and maintained on a 12-h light-dark cycle (06:00 to 18:00). Food

856 and water were available ad libitum. Mice ( 8 to 9 weeks old) were inoculated with $1 \times 10^{4}$ focus

857 forming units of SARS-CoV-2 (viral titer was determined on Vero-TMPRSS2-ACE2 cells) via

858 the intranasal route. Anti-SARS-CoV-2 human mAbs or isotype control mAbs were administered

$85924 \mathrm{~h}$ before (prophylaxis) SARS-CoV-2 inoculation. Weights and lethality were monitored daily

860 for up to 6 days after inoculation and mice were euthanized at 6 dpi and tissues were collected.

862 Epitope mapping of antibodies by alanine-scanning mutagenesis. Epitope mapping was

863 performed essentially as described previously (Davidson and Doranz, 2014) using a SARS-CoV-

8642 (strain Wuhan-Hu-1) spike protein NTD shotgun mutagenesis mutation library, made using a

865 full-length expression construct for spike protein, where 215 residues of the NTD (between spike

866 residues 9 and 310) were mutated individually to alanine, and alanine residues to serine.

867 Mutations were confirmed by DNA sequencing, and clones arrayed in a 384-well plate, one

868 mutant per well. Binding of mAbs to each mutant clone in the alanine scanning library was

869 determined, in duplicate, by high-throughput flow cytometry. A plasmid encoding cDNA for

870 each spike protein mutant was transfected into HEK-293T cells and allowed to express for $22 \mathrm{~h}$.

871 Cells were fixed in 4\% (v/v) paraformaldehyde (Electron Microscopy Sciences), and

872 permeabilized with $0.1 \%(w / v)$ saponin (Sigma-Aldrich) in PBS plus calcium and magnesium

873 (PBS++) before incubation with mAbs diluted in PBS++, 10\% normal goat serum (Sigma), and

$8740.1 \%$ saponin. MAb screening concentrations were determined using an independent 
875 immunofluorescence titration curve against cells expressing wild-type S protein to ensure that

876 signals were within the linear range of detection. Antibodies were detected using $3.75 \mu \mathrm{g} / \mathrm{mL}$ of

877 Alexa-Fluor-488-conjugated secondary antibodies (Jackson ImmunoResearch Laboratories) in

$87810 \%$ normal goat serum with $0.1 \%$ saponin. Cells were washed three times with PBS++/0.1\%

879 saponin followed by two washes in PBS, and mean cellular fluorescence was detected using a

880 high-throughput Intellicyte iQue flow cytometer (Sartorius). Antibody reactivity against each

881 mutant S protein clone was calculated relative to wild-type S protein reactivity by subtracting the

882 signal from mock-transfected controls and normalizing to the signal from wild-type S-transfected

883 controls. Mutations within clones were identified as critical to the mAb epitope if they did not

884 support reactivity of the test MAb but supported reactivity of other SARS-CoV-2 antibodies.

885 This counter-screen strategy facilitates the exclusion of $\mathrm{S}$ protein mutants that are locally 886 misfolded or have an expression defect.

888 Measurement of viral burden. Plaque assays were performed as described previously (Case et 889 al., 2020; Hassan et al., 2020) on Vero+TMPRSS2+hACE2 cells. Briefly, lung homogenates 890 were serially diluted and added to Vero+TMPRSS2+hACE2 cell monolayers in 12-well plates. 891 Plates were incubated at $37 \square^{\circ} \mathrm{C}$ for $1 \mathrm{~h}$ and then overlaid with $1 \%(\mathrm{w} / \mathrm{v})$ methylcellulose in 892 MEM supplemented with 2\% FBS. Plates were incubated at $37 \square^{\circ} \mathrm{C}$ for $72 \mathrm{~h}$ and were then fixed 893 with 4\% PFA for 20 min. Plaques were visualized by staining with $0.05 \%$ crystal violet in $20 \%$ 894 methanol. 
Quantification and statistical analysis. Mean \pm S.E.M. or mean \pm S.D. were determined for continuous variables as noted. Technical and biological replicates are described in the figure legends. For analysis of mouse studies, the comparison of weight-change curves was performed using a one-way ANOVA with Dunnett's post hoc test of the area under the curve for days 3-6 post-infection, using Prism v.9.0 (GraphPad). Infectious viral loads were compared by a one-way ANOVA with Dunnett's multiple comparisons test using Prism v.9.0 (GraphPad).

Figure S1. Divergence from inferred germline gene sequences, related to Figure 2

A. The number of mutations of each mAb relative to the inferred germline variable gene was violin plots. For the heavy chain, values range from 80.4 to 100 , with a median of 96.6 , a 25 th with a median of 97.9 , a 25 th quartile of 96.5 and a 75 th quartile of 98.9 . times same IGHV appeared and on $\mathrm{x}$-axis is the IGHV gene identified.

911 A. The first gate is for all cells, the second gate is for infected cells, and the third gate is for 912 antibody binding to infected cells. 
917 available from sequences 1) deposited in public databases shown in cyan color, 2) from

918 vaccinated individuals shown in purple, or 3) from infected individuals shown in orange.

919 Figure S4. Competition ELISA of mAbs, related to Figure 4

920 Competition ELISA of mAbs with previously mapped antibodies COV2-2130, COV2-2196,

921 COV2-2676, COV2-2489, r4A8 or rCR3022. Unlabeled antibodies applied to antigen first are

922 indicated on the left, while biotinylated antibodies that were added to antigen-coated wells

923 second are listed across the top. The number in each box represents the percent competition

924 binding of the biotinylated antibody in the presence of the indicated competing antibody. Heat

925 map colors range from dark grey ( $100 \%$ blocking of the biotinylated antibody) to white $(0 \%$ or

926 no blocking of the biotinylated antibody).

927 Figure S5. Epitope identification and characterization of COV2-3439, related to Figure 4

928 Residues critical for COV2-3439 binding, identified by screening COV2-3439 on an NTD 929 alanine-scan mutagenesis library, are shown in red spheres on the NTD (PDB 7L2C).

Figure S6. Structural characterization of COV2-3434, related to Figure 5

931 Steric clash of COV2-3434 Fab (green) with SARS-CoV2- S monomer (cyan) in open 932 conformation when modeled double Fab (COV2-3434 Fab (green) COV2-3439 Fab (magenta) + 933 rNTD (blue) complex on to SARS-CoV2- S monomer (cyan) in open conformation.

934 Figure S7. Neutralization of VSV-S by COV2-3434 related to Figure 5

935 A. Neutralization of VSV-S by COV2-3434 was measured in the absence or presence of $0.02 \%$ 936 polysorbate-80 in Vero-CCL81 cells. 
937 B. Neutralization of VSV-S by COV2-3434 was measured in the absence or presence of $25 \mu \mathrm{M}$

938 biliverdin in Vero-CCL81 cells.

939 Figure S8. Protection in K18 hACE2 transgenic mice by trimer-disrupting antibody COV2-

$940 \quad 3434$, related to Figure 6.

941 Eight-week-old female K18-hACE2 transgenic mice were inoculated by the intranasal route with

942104 FFU of SARS-CoV-2 (WA1/2020 D614G). One day prior to virus inoculation, mice were

943 given a single $1 \mathrm{mg}$ dose of COV2-3434, COV2-2196, or isotype control mAb by intraperitoneal

944 injection. Data are from two independent experiments, $\mathrm{n}=7$ (isotype) or 8 (all other groups).

945 A. Weight was monitored daily. Two-way ANOVA with Dunnett's post-test with comparison to 946 control mAb: **, $\mathrm{p}<0.001 ; *, \mathrm{p}<0.05 ; \mathrm{ns}$, not significant.

947 B. At 6 dpi, tissues were collected, and viral RNA levels in indicated tissues were determined

948 (line indicates median). One-way ANOVA with Dunnett's post-test: ****, p<0.0001; *p<0.05;

949 ns, not significant. The dotted line represents the limit of detection (LOD) of the assay. 


\section{REFERENCES}

963 Alamyar, E., Duroux, P., Lefranc, M.P., and Giudicelli, V. (2012). IMGT((R)) tools for the 964 nucleotide analysis of immunoglobulin (IG) and $\mathrm{T}$ cell receptor (TR) V-(D)-J repertoires, 965 polymorphisms, and IG mutations: IMGT/V-QUEST and IMGT/HighV-QUEST for NGS. 966 Methods Mol Biol 882, 569-604.

967

968 Amraei, R., Yin, W.Q., Napoleon, M.A., Suder, E.L., Berrigan, J., Zhao, Q., Olejnik, J., 969 Chandler, K.B., Xia, C.S., Feldman, J., et al. (2021). CD209L/L-SIGN and CD209/DC-SIGN 970 Act as Receptors for SARS-CoV-2. Acs Central Sci 7, 1156-1165.

971

972 Avanzato, V.A., Matson, M.J., Seifert, S.N., Pryce, R., Williamson, B.N., Anzick, S.L., Barbian, 973 K., Judson, S.D., Fischer, E.R., Martens, C., et al. (2020). Case Study: Prolonged Infectious 974 SARS-CoV-2 Shedding from an Asymptomatic Immunocompromised Individual with Cancer. 975 Cell 183, 1901-1912 e1909. 
977 Awasthi, M., Gulati, S., Sarkar, D.P., Tiwari, S., Kateriya, S., Ranjan, P., and Verma, S.K.

978 (2020). The Sialoside-Binding Pocket of SARS-CoV-2 Spike Glycoprotein Structurally

979 Resembles MERS-CoV. Viruses 12.

980

981

Baden, L.R., El Sahly, H.M., Essink, B., Kotloff, K., Frey, S., Novak, R., Diemert, D., Spector,

S.A., Rouphael, N., Creech, C.B., et al. (2021). Efficacy and Safety of the mRNA-1273 SARS-

983

CoV-2 Vaccine. N Engl J Med 384, 403-416.

984

985

Bangaru, S., Lang, S., Schotsaert, M., Vanderven, H.A., Zhu, X., Kose, N., Bombardi, R., Finn,

J.A., Kent, S.J., Gilchuk, P., et al. (2019). A Site of Vulnerability on the Influenza Virus

\section{7}

988

989

990

991

992

993

Hemagglutinin Head Domain Trimer Interface. Cell 177, 1136-1152 e1118.

Barnes, C.O., Jette, C.A., Abernathy, M.E., Dam, K.A., Esswein, S.R., Gristick, H.B., Malyutin, A.G., Sharaf, N.G., Huey-Tubman, K.E., Lee, Y.E., et al. (2020). SARS-CoV-2 neutralizing antibody structures inform therapeutic strategies. Nature 588, 682-687.

996

997 Cantuti-Castelvetri, L., Ojha, R., Pedro, L.D., Djannatian, M., Franz, J., Kuivanen, S., van der 998 Meer, F., Kallio, K., Kaya, T., Anastasina, M., et al. (2020). Neuropilin-1 facilitates SARS-CoV9992 cell entry and infectivity. Science 370, 856-860. 
1001 Case, J.B., Rothlauf, P.W., Chen, R.E., Liu, Z., Zhao, H., Kim, A.S., Bloyet, L.M., Zeng, Q.,

1002 Tahan, S., Droit, L., et al. (2020). Neutralizing Antibody and Soluble ACE2 Inhibition of a 1003 Replication-Competent VSV-SARS-CoV-2 and a Clinical Isolate of SARS-CoV-2. Cell Host 1004 Microbe 28, 475-485 e475.

1005

1006 Cerutti, G., Guo, Y., Wang, P., Nair, M.S., Wang, M., Huang, Y., Yu, J., Liu, L., Katsamba, P.S., 1007 Bahna, F., et al. (2021a). Neutralizing antibody 5-7 defines a distinct site of vulnerability in 1008 SARS-CoV-2 spike N-terminal domain. Cell Rep 37, 109928.

Cerutti, G., Guo, Y., Zhou, T., Gorman, J., Lee, M., Rapp, M., Reddem, E.R., Yu, J., Bahna, F., terminal domain target a single supersite. Cell Host \& Microbe 29, 819-833.e817.

1014 Chen, E.C., Gilchuk, P., Zost, S.J., Suryadevara, N., Winkler, E.S., Cabel, C.R., Binshtein, E., 1015 Chen, R.E., Sutton, R.E., Rodriguez, J., et al. (2021a). Convergent antibody responses to the 1016 SARS-CoV-2 spike protein in convalescent and vaccinated individuals. Cell Rep 36, 109604.

1018 Chen, R.E., Winkler, E.S., Case, J.B., Aziati, I.D., Bricker, T.L., Joshi, A., Darling, T.L., Ying, 1019 B., Errico, J.M., Shrihari, S., et al. (2021b). In vivo monoclonal antibody efficacy against SARS1020 CoV-2 variant strains. Nature 596, 103-108. 
1022

1023

1024

1025

1026

1027

1028

1029

1030

1031

1032

1033

1034

1035

1036

1037

1038

1039

1040

1041

1042

1043

Chi, X., Yan, R., Zhang, J., Zhang, G., Zhang, Y., Hao, M., Zhang, Z., Fan, P., Dong, Y., Yang, Y., et al. (2020). A neutralizing human antibody binds to the N-terminal domain of the Spike protein of SARS-CoV-2. Science 369, 650-655.

Chng, J., Wang, T., Nian, R., Lau, A., Hoi, K.M., Ho, S.C., Gagnon, P., Bi, X., and Yang, Y. (2015). Cleavage efficient 2A peptides for high level monoclonal antibody expression in CHO cells. MAbs 7, 403-412.

Choi, B., Choudhary, M.C., Regan, J., Sparks, J.A., Padera, R.F., Qiu, X., Solomon, I.H., Kuo, H.H., Boucau, J., Bowman, K., et al. (2020). Persistence and Evolution of SARS-CoV-2 in an Immunocompromised Host. N Engl J Med 383, 2291-2293.

Daly, J.L., Simonetti, B., Klein, K., Chen, K.E., Williamson, M.K., Anton-Plagaro, C., Shoemark, D.K., Simon-Gracia, L., Bauer, M., Hollandi, R., et al. (2020). Neuropilin-1 is a host factor for SARS-CoV-2 infection. Science 370, 861.

Davidson, E., and Doranz, B.J. (2014). A high-throughput shotgun mutagenesis approach to mapping B-cell antibody epitopes. Immunology 143, 13-20. 
1045 Gilchuk, P., Bombardi, R.G., Erasmus, J.H., Tan, Q., Nargi, R., Soto, C., Abbink, P., Suscovich,

1046 T.J., Durnell, L.A., Khandhar, A., et al. (2020). Integrated pipeline for the accelerated discovery

1047 of antiviral antibody therapeutics. Nat Biomed Eng 4, 1030-1043.

1048

1049 Golden, J.W., Cline, C.R., Zeng, X., Garrison, A.R., Carey, B.D., Mucker, E.M., White, L.E.,

1050 Shamblin, J.D., Brocato, R.L., Liu, J., et al. (2020). Human angiotensin-converting enzyme 2 1051 transgenic mice infected with SARS-CoV-2 develop severe and fatal respiratory disease. JCI

1052 Insight 5.

1053

1054 Greaney, A.J., Starr, T.N., Gilchuk, P., Zost, S.J., Binshtein, E., Loes, A.N., Hilton, S.K.,

1055 Huddleston, J., Eguia, R., Crawford, K.H.D., et al. (2021). Complete Mapping of Mutations to 1056 the SARS-CoV-2 Spike Receptor-Binding Domain that Escape Antibody Recognition. Cell Host 1057 Microbe 29, 44-57 e49.

1058

1059 Gupta, N.T., Vander Heiden, J.A., Uduman, M., Gadala-Maria, D., Yaari, G., and Kleinstein, 1060 S.H. (2015). Change-O: a toolkit for analyzing large-scale B cell immunoglobulin repertoire 1061 sequencing data. Bioinformatics 31, 3356-3358.

1062

1063 Hansen, J., Baum, A., Pascal, K.E., Russo, V., Giordano, S., Wloga, E., Fulton, B.O., Yan, Y.,

1064 Koon, K., Patel, K., et al. (2020). Studies in humanized mice and convalescent humans yield a 1065 SARS-CoV-2 antibody cocktail. Science 369, 1010-1014. 
1067

1068

1069

1070

1071

1072

1073

1074

1075

1076

1077

1078

1079

1080

1081

1082

1083

1084

1085

1086

1087

1088

Hassan, A.O., Case, J.B., Winkler, E.S., Thackray, L.B., Kafai, N.M., Bailey, A.L., McCune, B.T., Fox, J.M., Chen, R.E., Alsoussi, W.B., et al. (2020). A SARS-CoV-2 Infection Model in Mice Demonstrates Protection by Neutralizing Antibodies. Cell 182, 744-753 e744.

Henderson, R., Edwards, R.J., Mansouri, K., Janowska, K., Stalls, V., Gobeil, S.M.C., Kopp, M., Li, D., Parks, R., Hsu, A.L., et al. (2020). Controlling the SARS-CoV-2 spike glycoprotein conformation. Nat Struct Mol Biol 27, 925-933.

Hsieh, C.L., Goldsmith, J.A., Schaub, J.M., DiVenere, A.M., Kuo, H.C., Javanmardi, K., Le, K.C., Wrapp, D., Lee, A.G., Liu, Y., et al. (2020). Structure-based design of prefusion-stabilized SARS-CoV-2 spikes. Science 369, 1501-1505.

Huang, J.C., Diaz, D., and Mousa, J.J. (2020). Antibody recognition of the Pneumovirus fusion protein trimer interface. Plos Pathogens 16.

Lempp, F.A., Soriaga, L.B., Montiel-Ruiz, M., Benigni, F., Noack, J., Park, Y.J., Bianchi, S., Walls, A.C., Bowen, J.E., Zhou, J., et al. (2021). Lectins enhance SARS-CoV-2 infection and influence neutralizing antibodies. Nature 598, 342-347.

Mastronarde, D.N. (2005). Automated electron microscope tomography using robust prediction of specimen movements. Journal of Structural Biology 152, 36-51. 
McCallum, M., De Marco, A., Lempp, F.A., Tortorici, M.A., Pinto, D., Walls, A.C., Beltramello, M., Chen, A., Liu, Z., Zatta, F., et al. (2021). N-terminal domain antigenic mapping reveals a site of vulnerability for SARS-CoV-2. Cell 184, 2332-2347 e2316.

McCarthy, K.R., Rennick, L.J., Nambulli, S., Robinson-McCarthy, L.R., Bain, W.G., Haidar, G., and Duprex, W.P. (2021). Recurrent deletions in the SARS-CoV-2 spike glycoprotein drive antibody escape. Science 371, 1139-1142.

Ohi, M., Li, Y., Cheng, Y., and Walz, T. (2004). Negative Staining and Image Classification Powerful Tools in Modern Electron Microscopy. Biol Proced Online 6, 23-34.

Oladunni, F.S., Park, J.G., Pino, P.A., Gonzalez, O., Akhter, A., Allue-Guardia, A., OlmoFontanez, A., Gautam, S., Garcia-Vilanova, A., Ye, C., et al. (2020). Lethality of SARS-CoV-2 infection in K18 human angiotensin-converting enzyme 2 transgenic mice. Nat Commun 11, 6122.

Pinto, D., Park, Y.J., Beltramello, M., Walls, A.C., Tortorici, M.A., Bianchi, S., Jaconi, S., Culap, K., Zatta, F., De Marco, A., et al. (2020). Cross-neutralization of SARS-CoV-2 by a human monoclonal SARS-CoV antibody. Nature 583, 290-295.

Polack, F.P., Thomas, S.J., Kitchin, N., Absalon, J., Gurtman, A., Lockhart, S., Perez, J.L., Perez Marc, G., Moreira, E.D., Zerbini, C., et al. (2020). Safety and Efficacy of the BNT162b2 mRNA Covid-19 Vaccine. N Engl J Med 383, 2603-2615. 
1112 Punjani, A., Rubinstein, J.L., Fleet, D.J., and Brubaker, M.A. (2017). cryoSPARC: algorithms

1113 for rapid unsupervised cryo-EM structure determination. Nature Methods 14, 290.

1115 Robbiani, D.F., Gaebler, C., Muecksch, F., Lorenzi, J.C.C., Wang, Z., Cho, A., Agudelo, M., 1116 Barnes, C.O., Gazumyan, A., Finkin, S., et al. (2020). Convergent antibody responses to SARS-

1117 CoV-2 in convalescent individuals. Nature 584, 437-442.

Rogers, T.F., Zhao, F., Huang, D., Beutler, N., Burns, A., He, W.T., Limbo, O., Smith, C., Song, G., Woehl, J., et al. (2020). Isolation of potent SARS-CoV-2 neutralizing antibodies and protection from disease in a small animal model. Science 369, 956-963.

1124 Parker, E., dos Santos, M.S., et al. (2021). SARS-CoV-2 can recruit a heme metabolite to evade antibody immunity. Science Advances 7. of B Cell Receptor Sequences to Antigen Specificity. Cell 179, 1636-1646 e1615.

1131 Shi, R., Shan, C., Duan, X., Chen, Z., Liu, P., Song, J., Song, T., Bi, X., Han, C., Wu, L., et al. 1132 (2020). A human neutralizing antibody targets the receptor-binding site of SARS-CoV-2. Nature 584, 120-124. 
1135

1136

1137

1138

1139

1140

1141

1142

1143

1144

1145

1146

1147

1148

1149

1150

1151

1152

1153

1154

1155

Shiakolas, A.R., Kramer, K.J., Wrapp, D., Richardson, S.I., Schafer, A., Wall, S., Wang, N., Janowska, K., Pilewski, K.A., Venkat, R., et al. (2021). Cross-reactive coronavirus antibodies with diverse epitope specificities and Fc effector functions. Cell Rep Med 2, 100313.

Soto, C., Bombardi, R.G., Branchizio, A., Kose, N., Matta, P., Sevy, A.M., Sinkovits, R.S., Gilchuk, P., Finn, J.A., and Crowe, J.E., Jr. (2019). High frequency of shared clonotypes in human B cell receptor repertoires. Nature 566, 398-402.

Suryadevara, N., Shrihari, S., Gilchuk, P., VanBlargan, L.A., Binshtein, E., Zost, S.J., Nargi, R.S., Sutton, R.E., Winkler, E.S., and Chen, E.C. (2021). Neutralizing and protective human monoclonal antibodies recognizing the N-terminal domain of the SARS-CoV-2 spike protein. Cell 184, 2316-2331.

Turner, H.L., Andrabi, R., Cottrell, C.A., Richey, S.T., Song, G., Callaghan, S., Anzanello, F., Moyer, T.J., Abraham, W., Melo, M., et al. (2021a). Disassembly of HIV envelope glycoprotein trimer immunogens is driven by antibodies elicited via immunization. Science Advances 7.

Turner, J.S., Kim, W., Kalaidina, E., Goss, C.W., Rauseo, A.M., Schmitz, A.J., Hansen, L., Haile, A., Klebert, M.K., Pusic, I., et al. (2021b). SARS-CoV-2 infection induces long-lived bone marrow plasma cells in humans. Nature 595, 421-425. 
1156 Turner, J.S., O'Halloran, J.A., Kalaidina, E., Kim, W., Schmitz, A.J., Zhou, J.Q., Lei, T., Thapa,

1157 M., Chen, R.E., Case, J.B., et al. (2021c). SARS-CoV-2 mRNA vaccines induce persistent

1158 human germinal centre responses. Nature 596, 109-113.

1159

1160 Voss, W.N., Hou, Y.J., Johnson, N.V., Delidakis, G., Kim, J.E., Javanmardi, K., Horton, A.P.,

1161 Bartzoka, F., Paresi, C.J., Tanno, Y., et al. (2021). Prevalent, protective, and convergent IgG

1162 recognition of SARS-CoV-2 non-RBD spike epitopes. Science 372, 1108-1112.

1163

1164 Weisblum, Y., Schmidt, F., Zhang, F., DaSilva, J., Poston, D., Lorenzi, J.C., Muecksch, F., 1165 Rutkowska, M., Hoffmann, H.H., Michailidis, E., et al. (2020). Escape from neutralizing 1166 antibodies by SARS-CoV-2 spike protein variants. Elife 9.

1167

1168 Winkler, E.S., Gilchuk, P., Yu, J., Bailey, A.L., Chen, R.E., Chong, Z., Zost, S.J., Jang, H., 1169 Huang, Y., Allen, J.D., et al. (2021). Human neutralizing antibodies against SARS-CoV-2 1170 require intact Fc effector functions for optimal therapeutic protection. Cell 184, 1804-1820 1171 e1816.

1173 Wrapp, D., Wang, N., Corbett, K.S., Goldsmith, J.A., Hsieh, C.L., Abiona, O., Graham, B.S., 1174 and McLellan, J.S. (2020). Cryo-EM structure of the 2019-nCoV spike in the prefusion 1175 conformation. Science 367, 1260-1263. 
1177 Wu, N.C., Yuan, M., Liu, H., Lee, C.D., Zhu, X., Bangaru, S., Torres, J.L., Caniels, T.G.,

1178 Brouwer, P.J.M., van Gils, M.J., et al. (2020). An Alternative Binding Mode of IGHV3-53

1179 Antibodies to the SARS-CoV-2 Receptor Binding Domain. Cell Rep 33, 108274.

1180

1181 Yuan, M., Liu, H., Wu, N.C., Lee, C.D., Zhu, X., Zhao, F., Huang, D., Yu, W., Hua, Y., Tien,

1182 H., et al. (2020). Structural basis of a shared antibody response to SARS-CoV-2. Science 369, 1183 1119-1123.

1185 Zost, S.J., Dong, J., Gilchuk, I.M., Gilchuk, P., Thornburg, N.J., Bangaru, S., Kose, N., Finn, 1186 J.A., Bombardi, R., Soto, C., et al. (2021). Canonical features of human antibodies recognizing 1187 the influenza hemagglutinin trimer interface. J Clin Invest 131.

1189 Zost, S.J., Gilchuk, P., Case, J.B., Binshtein, E., Chen, R.E., Nkolola, J.P., Schafer, A., Reidy, 1190 J.X., Trivette, A., Nargi, R.S., et al. (2020a). Potently neutralizing and protective human 1191 antibodies against SARS-CoV-2. Nature 584, 443-449.

1193 Zost, S.J., Gilchuk, P., Chen, R.E., Case, J.B., Reidy, J.X., Trivette, A., Nargi, R.S., Sutton, R.E., 1194 Suryadevara, N., Chen, E.C., et al. (2020b). Rapid isolation and profiling of a diverse panel of 1195 human monoclonal antibodies targeting the SARS-CoV-2 spike protein. Nat Med 26, 1422-1427. 
Figure 1

A

Binding by antibodies in donor serum or plasma

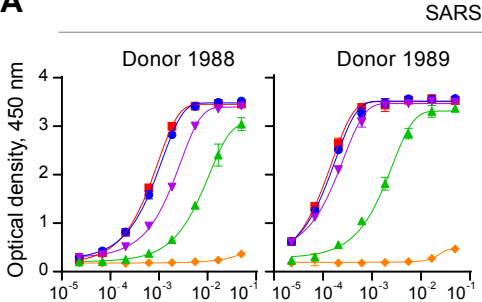

SARS-CoV-2-immune

Non-immune

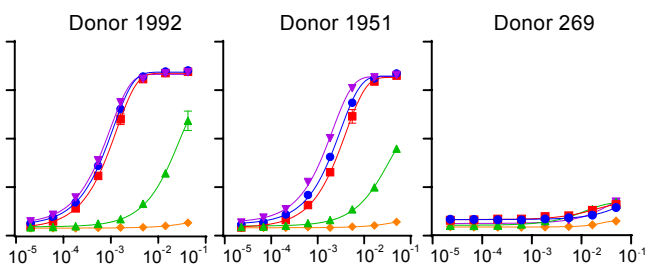

Dilution, serum or plasma

$\rightarrow$ SARS-CoV-2 S2P ecto $^{-} \rightarrow$ SARS-CoV-2 RBD $\rightarrow$ SARS-CoV-2 NTD $\rightarrow$ SARS-CoV S2P ${ }_{\text {ecto }} \rightarrow$ PBS

Neutralization by antibodies in donor 1989 serum or plasma

B

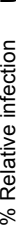

C Authentic SARS-CoV-2 (WA-1/2020)

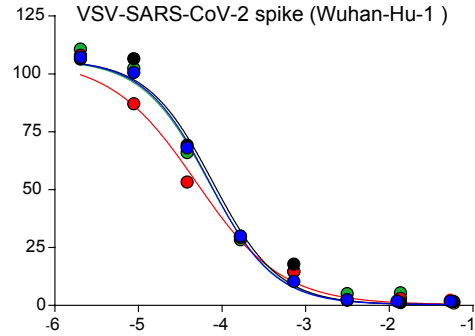

$-1-6$

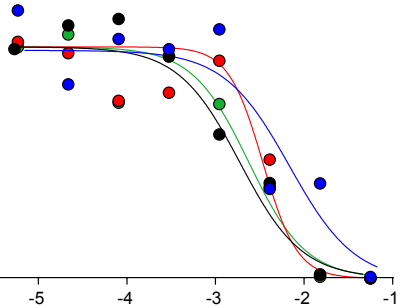

Day 18

- Day 28

- Day 56

- Day 90

$\log _{10}$ serum dilution 
A

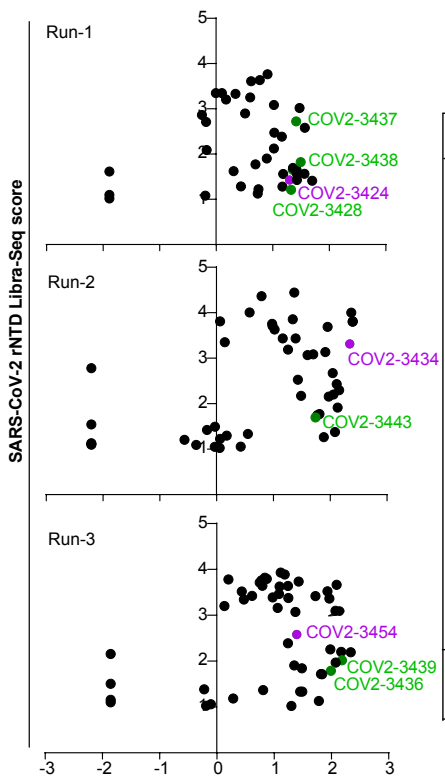

SARS-CoV-2 S6P ecto Libra-Seq score

B

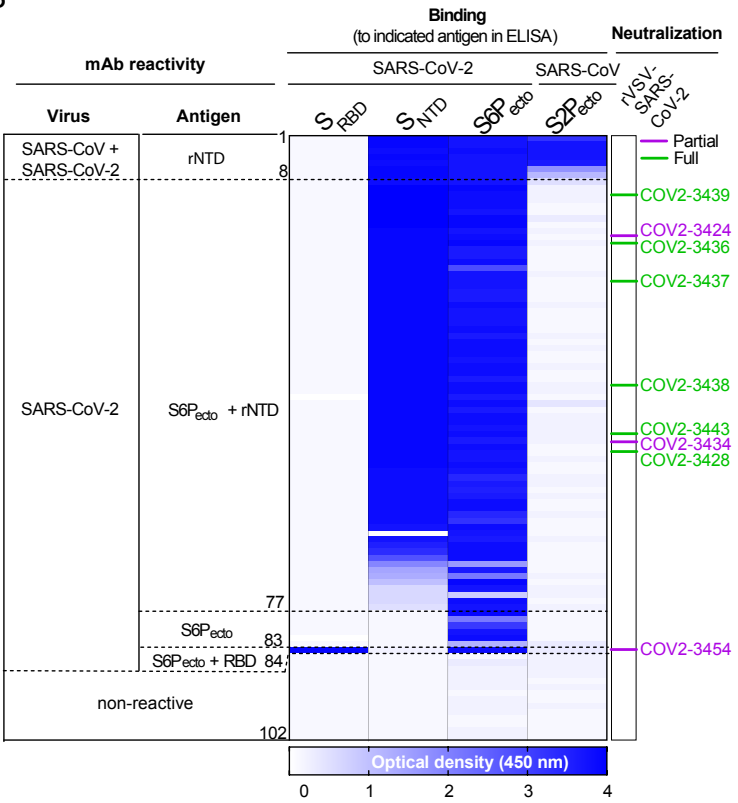

C

\begin{tabular}{|c|c|c|c|c|c|c|c|c|c|c|c|}
\hline \multirow{3}{*}{ mAb } & \multicolumn{2}{|c|}{ Heavy chain genes } & \multicolumn{2}{|c|}{ Light chain genes } & \multicolumn{4}{|c|}{$\begin{array}{c}\text { ELISA reactivity } \\
\text { (OD at } 450 \mathrm{~nm} \text { for indicated antigen) }\end{array}$} & \multicolumn{3}{|c|}{$\begin{array}{l}\text { LIBRA-Seq score } \\
\text { (for indicated antigen) }\end{array}$} \\
\hline & \multirow{2}{*}{$I G H V$} & \multirow{2}{*}{$I G H J$} & \multirow{2}{*}{$I G L V$} & \multirow{2}{*}{$I G L J$} & \multicolumn{3}{|c|}{ SARS-CoV-2 } & \multirow{2}{*}{\begin{tabular}{|l} 
SARS-COV \\
S2P $\mathrm{P}_{\text {ecto }}$ \\
\end{tabular}} & \multicolumn{2}{|c|}{ SARS-CoV-2 } & \multirow{2}{*}{$\begin{array}{l}\text { SARS-CoV } \\
{\mathrm{S} 2 \mathrm{P}_{\text {ecto }}}\end{array}$} \\
\hline & & & & & $\mathrm{S}_{\mathrm{RBD}}$ & $S_{\text {NTD }}$ & $\mathrm{S} \mathrm{P}_{\text {ecto }}$ & & $S_{\text {NTD }}$ & $\mathrm{S} \mathrm{P}_{\text {ecto }}$ & \\
\hline cov2-3424 & $3-23^{*} 01$ & $4^{*} 02$ & $3-1 * 01$ & $1 * 01$ & 0.1 & 3.9 & 2.8 & 0.1 & 2.7 & 1.2 & -2.3 \\
\hline cov2-3428 & $3-53^{*} 01$ & $3^{*} 02$ & $1-5^{\star} 03$ & $1^{*} 01$ & 0.1 & 3.8 & 3.6 & 0.2 & 1.4 & 1.3 & 0.3 \\
\hline cov2-3434 & $1-2^{*} 02$ & $3^{*} 02$ & $1-44^{*} 01$ & $3 * 02$ & 0.1 & 3.8 & 3.4 & 0.2 & 3.3 & 2.3 & -0.8 \\
\hline cov2-3436 & $1-24^{*} 01$ & $4^{\star} 02$ & $1-40 * 01$ & $2^{*} 01$ & 0.1 & 3.9 & 3.7 & 0.1 & 2.0 & 2.2 & -0.3 \\
\hline COV2-3437 & $"$ & $5^{\star} 02$ & $3-20^{\star} 01$ & $1^{*} 01$ & 0.1 & 3.9 & 3.6 & 0.2 & 1.7 & 1.4 & -0.1 \\
\hline cov2-3438 & $"$ & $"$ & $2-23^{*} 02$ & $2 * 01$ & 0.1 & 3.8 & 3.8 & 0.1 & 1.8 & 1.5 & -0.9 \\
\hline cov2--3439 & $"$ & $"$ & $1-39 * 01$ & $1 * 01$ & 0.1 & 4.0 & 3.8 & 0.1 & 1.8 & 2.0 & 0.6 \\
\hline cov2-3443 & $"$ & $6^{*} 02$ & $1-44^{*} 01$ & $3^{*} 02$ & 0.1 & 3.9 & 3.8 & 0.1 & 1.7 & 1.7 & -2.4 \\
\hline
\end{tabular}




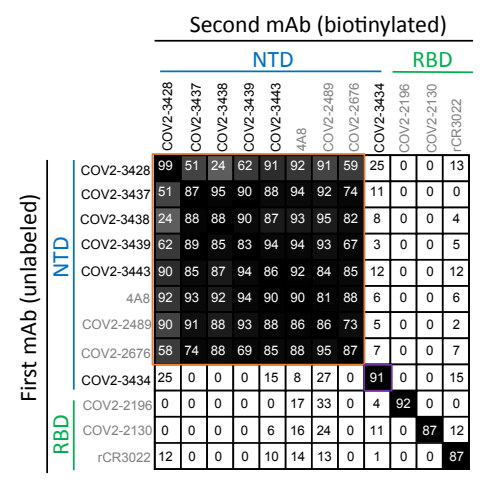

C SARS-CoV-2 S6P only

\section{No Fab}

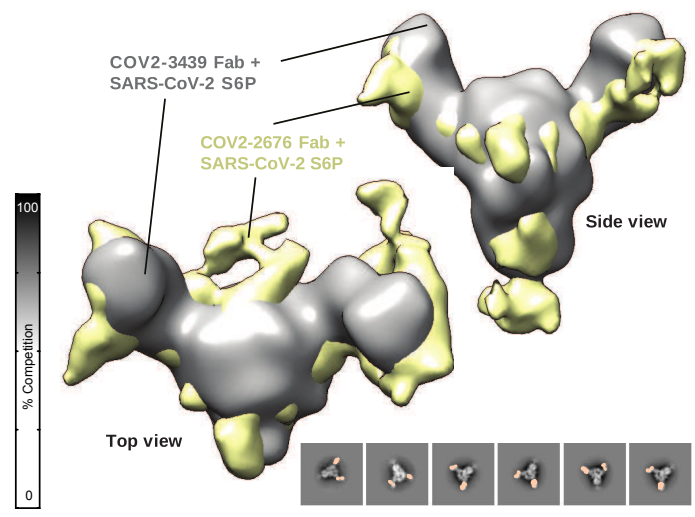

COV2-3434 Fab + SARS-CoV-2 S6P

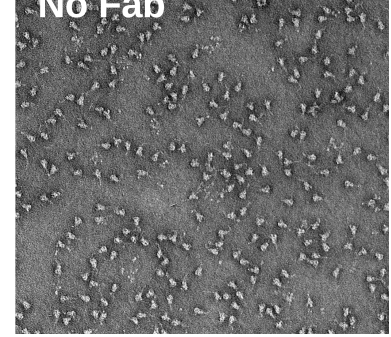

\section{$0 \mathrm{~min}$}

\section{$1 \mathrm{~min}$}

\section{$60 \mathrm{~min}$}

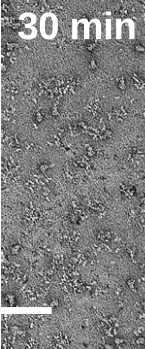

\section{$5 \mathrm{~min}$}




\section{Figure 5}

A

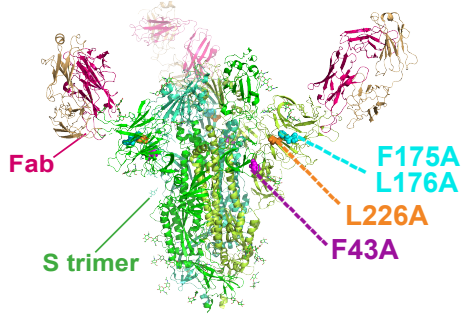

B

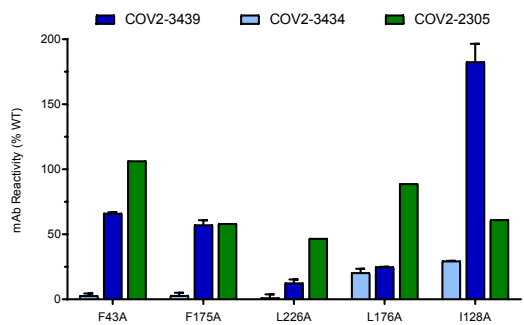

C

rNTD + Double Fab complex

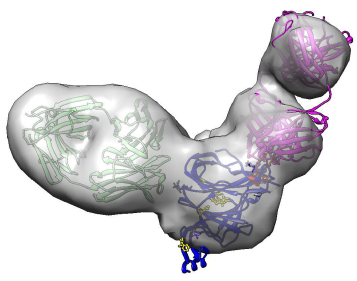

CoV2-2130

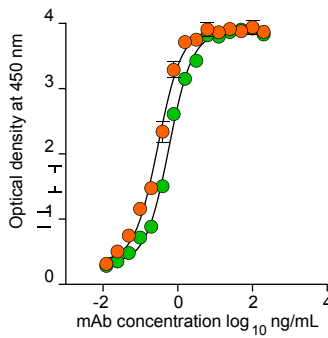

COV2-2676
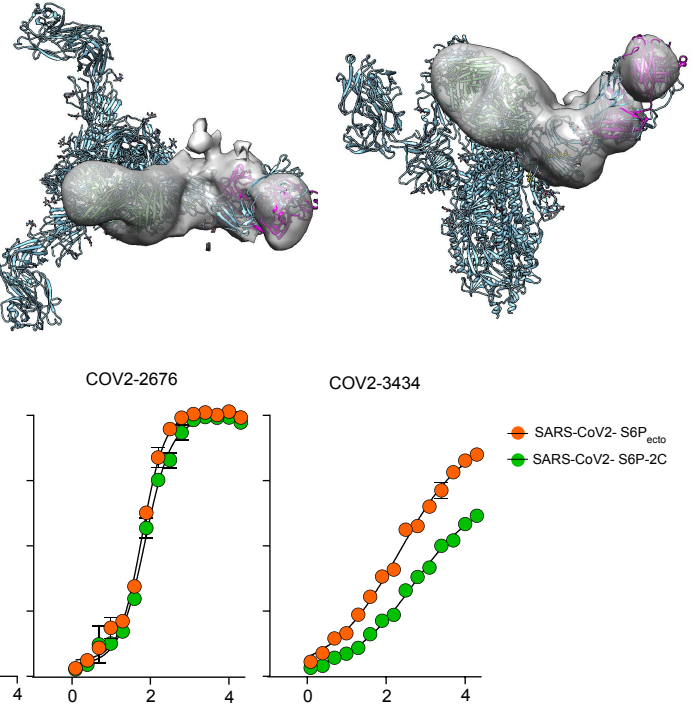

Cov2-3434

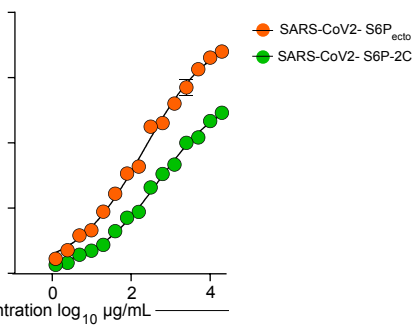

$E$

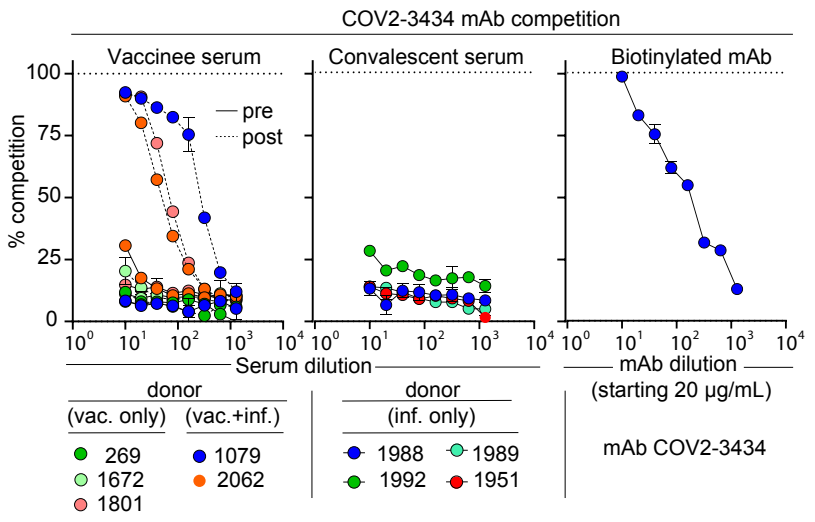


Escape virus selection using rVSV-SARS-CoV-2 $S \Delta 21$

\begin{tabular}{|c|c|c|c|c|c|c|c|}
\hline \multirow[b]{2}{*}{ Antigen } & \multirow[b]{2}{*}{ Antibody } & \multirow{2}{*}{$\begin{array}{c}\text { Confirmed } \\
\text { escape at } \\
\text { indicated } \\
\text { concentration } \\
\text { of mAb }\end{array}$} & \multirow{2}{*}{$\begin{array}{l}\text { Mutation } \\
\text { selected }\end{array}$} & \multirow[b]{2}{*}{ Reference } & \multicolumn{3}{|c|}{ RTCA neutralization data } \\
\hline & & & & & $\begin{array}{c}\text { COV2- } \\
3434 \\
(20 \mu \mathrm{g} / \mathrm{mL})\end{array}$ & $\begin{array}{c}\text { COV2- } \\
2196 \\
(5 \mu \mathrm{g} / \mathrm{mL})\end{array}$ & $\begin{array}{c}\text { Escape } \\
\text { virus } \\
\text { only }\end{array}$ \\
\hline Wild-type S & N/A & N/A & N/A & $\begin{array}{c}\text { Case et al., } \\
2020\end{array}$ & & & \\
\hline \multirow{5}{*}{ RBD } & Cov2-2130 & \multirow{5}{*}{$5 \mu \mathrm{g} / \mathrm{mL}$} & K444R & $\begin{array}{c}\text { Dong et al., } \\
2021\end{array}$ & & & \\
\hline & COV2-2094 & & K378E & $\begin{array}{c}\text { Greaney et al., } \\
2020\end{array}$ & & & \\
\hline & Cov2-2479 & & E484K & $"$ & & & \\
\hline & COV2-2499 & & G466D & $"$ & & & \\
\hline & Cov2-2499 & & Q498R & $"$ & & & \\
\hline \multirow{3}{*}{ NTD } & COV2-2489 & \multirow{2}{*}{$100 \mu \mathrm{g} / \mathrm{mL}$} & R158S & $\begin{array}{c}\text { Suryadevara et al., } \\
2021\end{array}$ & & & \\
\hline & COV2-2489 & & G142D & $"$ & & & \\
\hline & Cov2- 2676 & $50 \mu \mathrm{g} / \mathrm{mL}$ & F140S & $"$ & & & \\
\hline
\end{tabular}

B

Weight change

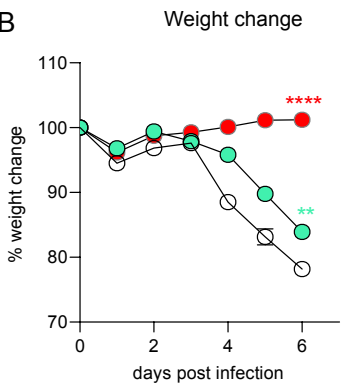

C

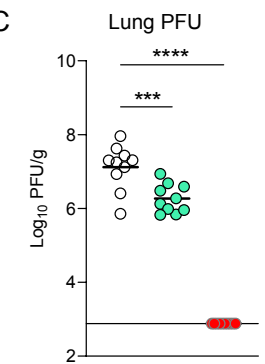

Cov2-3434

COV2-2196

rDENV-2D22 